\title{
Optimization of engineered super donor strains of Cryphonectria parasitica to reduce canker expansion in a forest setting
}

Amy Michelle Metheny

ammetheny@mix.wvu.edu

Follow this and additional works at: https://researchrepository.wvu.edu/etd

Part of the Plant Pathology Commons

\section{Recommended Citation}

Metheny, Amy Michelle, "Optimization of engineered super donor strains of Cryphonectria parasitica to reduce canker expansion in a forest setting" (2019). Graduate Theses, Dissertations, and Problem Reports. 3818.

https://researchrepository.wvu.edu/etd/3818

This Thesis is protected by copyright and/or related rights. It has been brought to you by the The Research Repository @ WVU with permission from the rights-holder(s). You are free to use this Thesis in any way that is permitted by the copyright and related rights legislation that applies to your use. For other uses you must obtain permission from the rights-holder(s) directly, unless additional rights are indicated by a Creative Commons license in the record and/ or on the work itself. This Thesis has been accepted for inclusion in WVU Graduate Theses, Dissertations, and Problem Reports collection by an authorized administrator of The Research Repository @ WVU. For more information, please contact researchrepository@mail.wvu.edu. 
Optimization of engineered super donor strains of Cryphonectria parasitica to reduce canker expansion in a forest setting

Amy M. Metheny

\author{
Thesis submitted \\ to the Davis College of Agriculture, Natural Resources and Design \\ at West Virginia University \\ in partial fulfillment of the requirements for the degree of \\ Master of Science in \\ Plant Pathology
}

\author{
Matthew T. Kasson, Ph.D., Chair \\ William L. MacDonald, Ph.D. \\ Donald L. Nuss, Ph.D. \\ Daniel G. Panaccione, Ph.D.
}

Division of Plant and Soil Sciences
Morgantown, West Virginia
2019

Keywords: Cryphonectria, American chestnut, biocontrol, chestnut blight, hypovirulence Copyright 2019 Amy Metheny 


\title{
Abstract \\ Optimization of engineered super donor strains of Cryphonectria parasitica to reduce canker expansion in a forest setting
}

\begin{abstract}
Amy Metheny
Chestnut blight, caused by the non-native fungus Cryphonectria parasitica, has decimated American chestnut (Castanea dentata) populations throughout the eastern U.S. over the last century. Biological control of blight, termed hypovirulence, has emerged naturally in the form of a debilitating hypovirus transmitted through hyphal anastomosis among vegetatively compatible C. parasitica strains. Six unlinked vegetative incompatibility (vic) loci regulate hyphal anastomosis and thus, hypovirus transmission, which has limited biocontrol efficacy in genotypically diverse communities. Recently, four of six vic loci have been disrupted to engineer two "super donor" or SD strains. In combining these strains, enhanced transmission of hypovirus to virulent strains is observed regardless of vic genotype of the recipient strain. Recently, the efficacy of the SD strains containing the CHV1/EP713 hypovirus has been field-tested on natural infections of American chestnut in a forest setting. Compared to a treatment containing hypovirulent EU-5/EU-6 strains, the SD treatment results in significant reduction in canker expansion and decreased mortality after one year. However, expansion between 4 and 12 months in previously controlled cankers raises concerns about application method and hypovirus efficacy. To explore performance optimization of SD strains, this study was initiated using the same SD strains with either the CHV1/Euro7 or CHV1/EP713 hypovirus on both natural and artificially-initiated cankers. Three application methods were used on cankers to deliver SD treatment inoculum: punch (previous study), scratch, or paint treatment. A total of 50 stems were assigned one hypovirus/application combination. Stems were measured quarterly and sampled at 12-months post inoculation. Canker expansion and mortality were monitored to permit short- and long-term comparisons. Overall, the punch application type and CHV1/Euro7 hypovirus showed greater inhibition of canker expansion. Canker size and recovery of hypovirus were correlated, suggesting that smaller canker sizes were a direct result of hypovirus transmission. The results of this study support further optimization through comparisons among hypovirus and application method to increase field efficacy of super donor formulations of $C$. parasitica.
\end{abstract}




\section{Acknowledgements}

Thank you to The Ohrstrom Foundation and The American Chestnut Foundation for funding this enlightening project. I want to acknowledge my chair and mentor, Matthew Kasson for always being the supportive whirlwind of knowledge and energy that I needed to push myself through this process, William MacDonald for introducing me to chestnut blight research six years ago and gently mentoring me ever since, Donald Nuss for literally engineering my study organism (and always being the one to laugh at my silly jokes), and Daniel Panaccione for his patient, tireless instruction and kind mentorship. To my incredible partner, Robert Eckenrode IV, for loving and guiding me through the ugliest, most stressful times of this process, and for always finding a way to put a smile on my face. To my parents, Dora and Jerry Metheny for your love and support. Mark Double, who is a father figure to us all, for being the mentor I needed and never letting me be too hard on myself. Without undergraduate guidance from Greg Dahle and John Brooks, I could have never organized myself enough, or gained the confidence to prepare for graduate school. I am forever grateful for Kristen Wickert, Cameron Stauder, and Angie Macias for helping in the field and lab, and for being the best coworkers and friends I could have hoped for. Thanks to the R Wizard, Chansotheary Dang, for assistance in creating figures, long nighttime discussions, and boosting all around morale. Ida Holaskova for your amazing guidance of a numerically-challenged individual through the world of statistics, and for your help in the field. To Lucy Morrison for keeping me in good spirits and always being a soft place to land. Thank you to Kristen Wickert, Mary Evers, Lukas Hill, Justin Stone, Nick Robertson, and Anthony Pappas for your endless witticisms and 24-7 support system. Without any of these people, I would never have completed this monster, and for that I am eternally grateful. Thank you for believing in me. 


\section{Table of Contents}

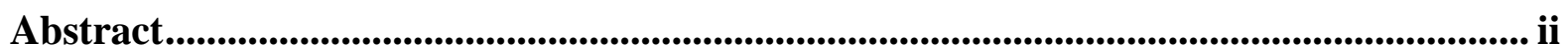

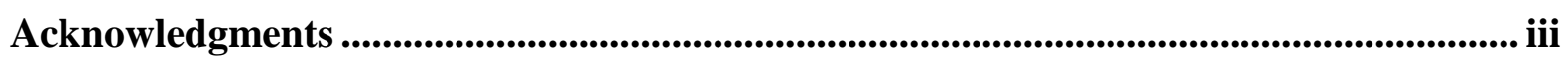

List of Tables ............................................................................................................................ vi

List of Figures................................................................................................................ vii

Chapter 1. Literature Review ...................................................................................1

The American chestnut (Castanea dentata) and its Decline ......................................................1

Cryphonectria parasitica: An Overview ………...............................................................

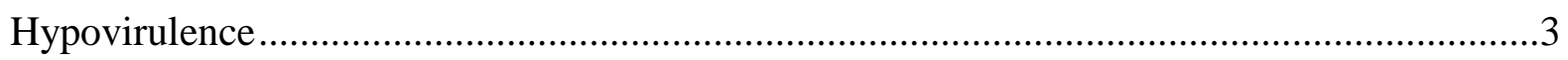

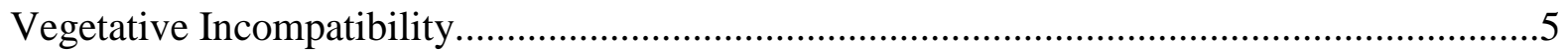

Engineered Super Mycovirus Donor Strains of C. parasitica ....................................................6

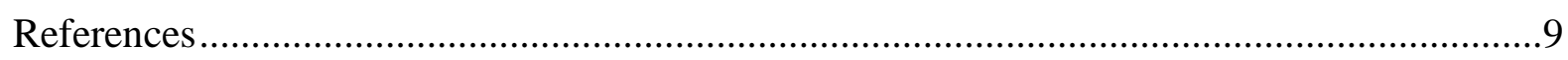

Chapter 2. Optimization of engineered super donor strains of Cryphonectria parasitica to reduce canker expansion in a forest setting.................................................................................. 13

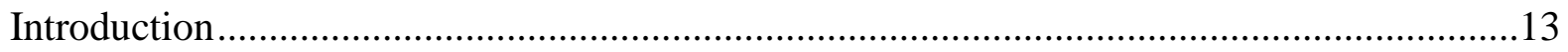

Materials and Methods..............................................................................................15

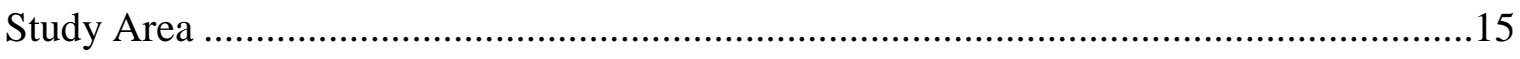

Selection of Canker Initiation Isolate ……………………...........................................16

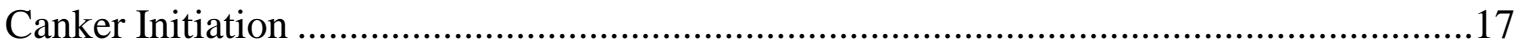

Treatment Inoculum Preparation ..................................................................................18

Canker Measurements, Treatment, and Sampling .................................................................19

Fungal Isolate Processing and Retention ......................................................................21

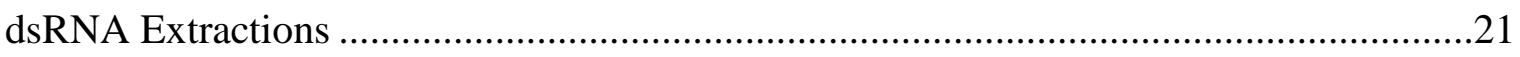

DNA Extraction and vic Genotyping ..........................................................................22

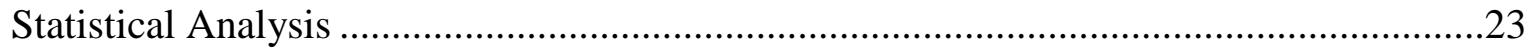

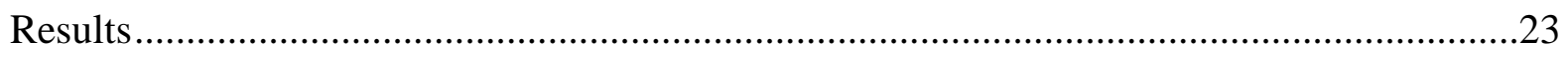

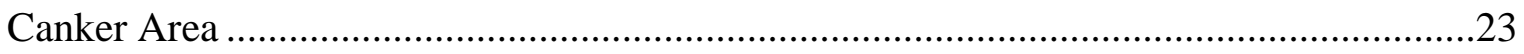

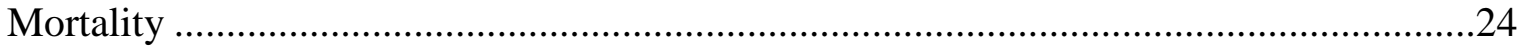

Recovery of C. parasitica ..........................................................................................25

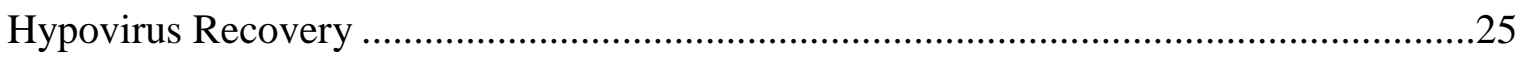




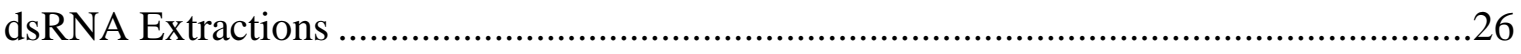

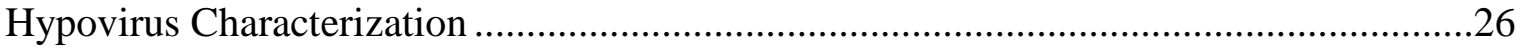

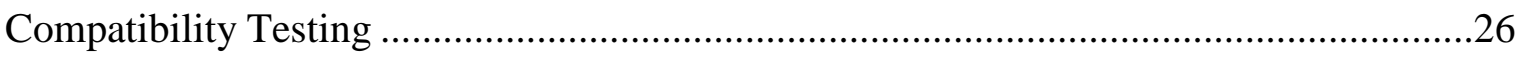

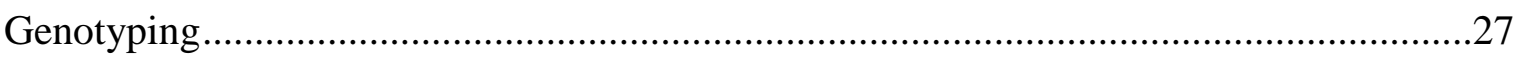

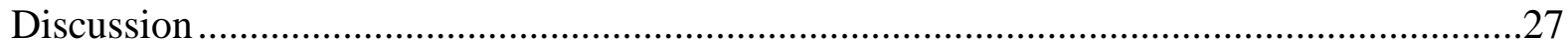

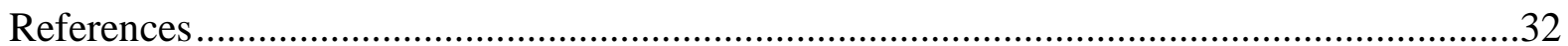




\section{List of Tables}

Table 1. Isolates of C. parasitica subjected to dsRNA extraction and their sources...................34

Table 2. Hypovirus sequencing results for isolates from which dsRNA was recovered. .............34

Table 3. Compatibility of $C$. parasitica isolates recovered from the six treatments....................35

Table 4. Vic genotypes of representative isolates from natural cankers in each treatment type...36

Table 5. Summary data for individual study trees. 


\section{List of Figures}

Figure 1. Pathogenicity assay of C. parasitica isolates in apples ..........................................38

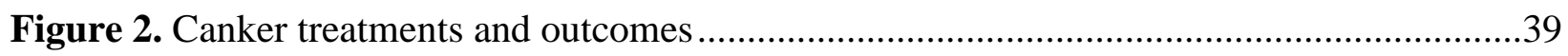

Figure 3. Average linear canker area by application method up to 12 MPI ............................40

Figure 4. Average linear canker area by hypovirus up to 12 MPI ........................................41

Figure 5. Average linear canker area by application type and hypovirus at 12 MPI.................42

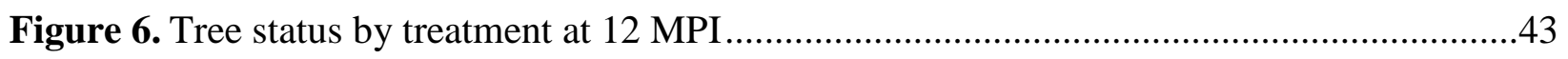

Figure 7. Atypical C. parasitica phenotypes recovered post-treatment...................................44 


\section{Chapter 1}

\section{Literature Review}

\section{The American chestnut (Castanea dentata) and its decline}

The American chestnut (Castanea dentata (Marsh.) Borkh.) is a large, fast-growing species in the family Fagaceae, which includes oak, beech, and chestnut. American chestnut is native to the Appalachian region, extending from northern Georgia to southern Maine (Hepting, 1974). Although this tree's annual nut crop was considered a major food source for humans and native wildlife, the most easily monetized indicator of its importance was is in its lumber value (Pinchot et al., 1897). Oftentimes dubbed the “cradle to grave tree” for its many uses and the likelihood that one will both lay in a cradle and a casket made of its wood, the American chestnut made up over one quarter of all hardwood timber in southern Appalachia before its disease-induced decline beginning in the early 1900s (Hepting, 1974). The deadly chestnut blight fungus, Cryphonectria parasitica (formerly Endothia parasitica), was inadvertently introduced to the United States from Asia on infected chestnut (Castanea spp.) nursery stock and quickly spread throughout the American chestnut's native range, wiping out nearly all large trees by 1960 (Jacobs, 2007). The killing front of $C$. parasitica infections spread at a rate of about 22 miles per year, nearly covering the extent of the American chestnut's native range in less than 50 years and leaving forests of dead, standing trees in its wake (Hepting, 1974). By 1950, an estimated 9 million acres of trees had been killed (Anagnostakis, 1982)

Since the discovery of chestnut blight many control strategies have been proposed and tested, the earliest of which included cutting and burning infected trees and culling uninfected trees along the killing front (Hepting, 1974). These early attempts to contain the advancement of C. parasitica proved futile and within a half century, this once stalwart of the forest was reduced to a short-lived understory tree with diminished ecological value and economic utility. However, 
over the last three plus decades, efforts to restore the American chestnut have gained traction with the establishment of The American Chestnut Foundation (TACF), using traditional breeding to cross naturally resistant Chinese chestnut (Castanea mollisima) trees with American chestnut to create blight-resistant trees with the form of the American chestnut (Diskin et al., 2006). These efforts have shown great potential, yet screens for resistance to other pervasive pathogens such as root rot (Phytophthora cinnamomi) have only been recently added to the breeding program (Zhebentyayeva et al., 2013). Over the same period, debilitating hypoviruses as biological controls of $C$. parasitica became a useful tool in combating chestnut blight. More recently, the development of transgenic American chestnut containing an inserted wheat gene that produces an oxalate detoxifying enzyme, have been at the forefront of chestnut blight control (Welch et al., 2007), focusing on increasing host resistance rather than decreasing the pathogenicity of $C$. parasitica.

\section{Cryphonectria parasitica: An overview}

Cryphonectria parasitica is one of five formally described Cryphonectria species in the order Diaporthales. Other known species include Cryphonectria macrospora (Tak. Kobay. \& Kaz. Ito) M.E. Barr, Cryphonectria nitschkei (G.H. Otth) M.E. Barr, Cryphonectria radicalis (Schwein.: Fr.) M. E. Barr, and Cryphonectria naterciae M.H. Braganca, E. Diogo, \& A.J.L. Phillips (Braganca et al., 2011, Gryzenhout et al., 2006 a, b, c). Of these five species, only C. parasitica is a primary plant pathogen, while the others tend to be primarily saprotrophic, acting as facultative opportunistic pathogens on weakened and dead trees (Myburg et al., 2004). C. parasitica and other known Cryphonectria species are distinguished by their orange stromatic tissues in which pycnidia are formed (Myburg et al., 2004). Perithecia, when present have 
slender perithecial necks and ellipsoid to fusoid, aseptate to uniseptate, hyaline ascospores and occur beneath the bark surface.

Cryphonectria parasitica can enter through any wound in the bark, including but not limited to broken branches, deer rub, and insect feeding. Once the fungus has entered the tree, it creates a radially-expanding area of necrosis in the cambial layer. $C$. parasitica attacks its host by secreting oxalic acid to facilitate tissue necrosis on various chestnut species, although American chestnut is by far the most susceptible (Anagnostakis, 1982). The interior of the cankers later produce orange, protective fungal stromata and the orange mycelium is often visible in the epidermis (Anagnostakis, 1987). The canker destroys the phloem, vascular cambium, and as it progresses inward cuts off the tree's xylem, which is responsible for the transportation of water and nutrients, resulting in death of the stem directly above the canker. Once the canker girdles the stem, all living tissue above that point dies, and the dead stem becomes what is essentially a standing inoculum reservoir. Generally, the root system of the stem stays alive, protected by the soil, and periodically sends up new vegetative shoots of those same chestnut genotypes long after the last large overstory trees have disappeared. Some trees with limited resistance may impede the growth of $C$. parasitica by producing callus tissue and effectually walling off the diseased area (Anagnostakis, 1982). However, the fungus may overcome the callused area, especially when trees are stressed.

\section{Hypovirulence}

The first recorded instance of blight-susceptible chestnut trees effectively shutting down $C$. parasitica cankers was on European chestnuts (Castanea sativa) in Italy in the 1950's (Biraghi, 1953). These trees were of a slightly more blight-resistant but still susceptible species, European 
chestnut (Castanea sativa), and exhibited cankers which had significantly arrested growth. Upon sampling, the plant pathologist Antonio Biraghi also discovered that the isolates displayed a muted, whitish pigmentation, as opposed to the bright orange of a normal C. parasitica isolate, as well as reduced production of conidia (MacDonald and Fulbright, 1991). However, the level of expression of hypovirus-associated traits varies wildly across hypovirus species and strains (Chen et al., 1999).

Hypoviruses in the CHV-1 group create the most obvious symptoms in infected $C$. parasitica isolates and are widely found naturally occurring in the environment in Europe and Asia. Likely the species Biraghi observed in Europe, CHV-1 hypoviruses reduce pigmentation, virulence of the fungus, and sporulation, thereby reducing the fungus's ability to rapidly colonize its host and spread to healthy chestnut stems (Linder-Basso et al., 2005). Hypoviruses in the CHV-2 group are found naturally in North America, most notably in New Jersey, U.S., and have been detected in China (Peever et al., 1998). Colonies infected with CHV-2 hypoviruses are debilitated in terms of sporulation and development, as well as virulence, although to a lesser extent than individuals infected with CHV-1 hypoviruses (Linder-Basso et al., 2005). CHV-3 and CHV-4 hypoviruses occur in North America, with CHV-3 hypoviruses documented mostly in Michigan, U.S. (Melzer et al., 1996, Linder-Basso et al., 2005). CHV-3 and CHV-4 hypoviruses have the least effect on C. parasitica, but still reduce fungal virulence when compared to wild-type strains (Linder-Basso et al., 2005).

Most hypovirulence research in North America and Europe in relation to C. parasitica focuses on CHV-1 hypoviruses. Causing the most pronounced phenotypic changes, the CHV1/EP713 hypovirus is the most intensively studied of the C. parasitica hypoviruses, and is often referred to as the prototypic virus (Dawe and Nuss, 2013). The CHV1/Euro7 hypovirus less 
severely effects C. parasitica than CHV1/EP713. Both strains induce white phenotypes in C. parasitica, however colonies infected with CHV1/EP713 typically grow more slowly, produce fewer conidia, and are more virulent when compared to colonies infected with CHV1/Euro7 (Hillman and Suzuki, 2004).

\section{Vegetative Incompatibility}

Transmission of hypoviruses from an infected individual of C. parasitica to a healthy individual is based on those individuals' vegetative incompatibility (vic) loci. In C. parasitica, there are six diallelic vic loci controlling compatibility, allowing for a total of 64 (based on $2^{6}$ possible combinations) commonly accepted genotypes. Previously, a seventh vic locus (known as vic5) was thought to be involved in determining an isolate's compatibility type, but it has since been determined that it does not have any effect on hypovirus transmission rates (Cortesi et al., 1998). The presence of differing alleles at vic4 also does not appear to affect hypovirus transmission, as incompatibility reactions between individuals differing at vic4 occur slowly enough to allow for hypovirus transmission (Cortesi et al., 2001). These genotypes are conventionally described by displaying which allele, 1 or 2, is present at each vic locus. For example, 2122-11 would describe an isolate with a vic genotype of vic1-2, vic2-1, vic3-2, vic4-2, vic6-1, vic7-1.

Individuals with identical vic genotypes can undergo hyphal anastomosis, a fusion of hyphal cells in which cytoplasmic material (including hypoviruses) can be transmitted between two colonies and a single colony is formed (Cortesi et al., 2001). Hyphae of two individuals with differing alleles at one or more of the six vic loci typically cannot anastomose, instead experiencing localized programmed cell death, in which cells in the hyphae between the two incompatible individuals die, forming a visible line of demarcation, and preventing most exchange of cytoplasmic material (Papazova-Anakieva et al., 2007). However, research has 
shown that some individuals with differing alleles are able to anastomose, a phenomenon more commonly seen in host tissue than in culture (Stauder et al., 2019). In general, individuals with the fewest number of heteroallelic vic loci are the most likely to achieve hypovirus transmission (Liu et al., 1996). However, the frequency at which these differing genotypes can transmit hypovirus are somewhat dependent on which genotype is the donor strain and which is the recipient (Huber et al., 1994).

Like most mycoviruses, C. parasitica hypoviruses have exclusively intracellular life cycles, giving them little-to-no viability outside of their host and limiting their ability to infect healthy fungal individuals through means other than hyphal anastomosis (Buck, 1986). As such, the most pronounced barrier to hypovirus transmission in populations of C. parasitica is diversity of vic genotypes. In fact, the assumption has long been that the evolutionary advantage of vegetative incompatibility is to reduce the spread of hypoviruses and other similar cytoplasmically-spread infections (Caten, 1972). Hypovirulence as a biocontrol has been much more successful in Europe, where wild populations of $C$. parasitica harbor relatively few vic genotypes, than in North America, in which many of the 64 vic genotypes have been recorded (Short et al., 2015).

\section{Engineered super mycovirus donor strains of $C$. parasitica}

The identification of genes associated with the C. parasitica vic loci at the molecular level (Choi et al., 2012; Zhang et al., 2014) allowed Zhang et al. (2016) genetically engineered a super hypovirus donor by disrupting four of the five vic loci which effect hypovirus transmission. The two vic2 alleles were refractory to donor-promoting gene disruptions. 
To address vegetative incompatibility (vic) of C. parasitica, Zhang and Nuss (2016) genetically engineered a super hypovirus donor by disrupting four of the five vic loci which effect hypovirus transmission using an adapted Cre-loxP recombination system (Zhang et al., 2016). Gene disruptions at the two vic2 alleles produced mutants that were either ineffective at hypovirus transmission or not viable. As a result, two super donor strains are necessary, each with a different allele at the vic2 locus. A disrupted EP155 strain (Z211-Z2) was crossed with the brown EP146 (2112-22) to create progeny containing the gene disruptions and a brown phenotype, SD328 (z211-z2) and SD82 (z111-z2). The genetic disruptions and brown phenotype allow SD strains to be easily genotypically and phenotypically distinguished from non-disrupted C. parasitica isolates. SD328 and SD82 isolates have been recorded to result in similarly sized cankers on cut $C$. dentata stems to those caused by wild-type strains of EP155, although cankers caused by SD328 were slightly smaller than those caused by SD82. However, when infected with the CHV1-EP713 hypovirus, both SD328 and SD82 produced cankers on excised C. dentata stems that were much smaller than those caused by wild-type EP155 strains.

When tested by Zhang and Nuss (2016), at least one of the two SD strains successfully transmitted hypovirus to the "16 tester strains that were heteroallelic at three or more vic loci," suggesting that a formulation of SD strains could be used to transmit hypovirus to any individual of C. parasitica regardless of vic genotype. While laboratory assays show SD strains to have a nearly $100 \%$ hypovirus transmission rate, environmental conditions may alter SD strain efficacy. Stauder et al., (2019) tested the feasibility of using SD strains as a control method for $C$. parasitica cankers on diseased living C. dentata stems on Savage River State Forest, MD.

Mixed formulations of hypovirulent $C$. parasitica strains representing a number of different vic genotypes to increase the chance of hypovirus conversion were first recorded by 
Jaynes et al. as early as 1980. In this early account, hypovirulent isolates of differing vic genotypes are grown on potato dextrose agar (PDA) (Difco) and macerated by blending with sterile distilled water. Stauder et al. (2019) uses a similar approach, blending colonies of SD328 and SD82 containing the CHV1/EP713 hypovirus grown on PDA with water agar and sterile water to create treatment inoculum. Treatment inoculum is created in a similar fashion using hypovirulent EU5 and EU6 tester strains (Cortesi et al., 1998) containing the CHV1/EP713 hypovirus, which have the same vic genotypes as SD328 and SD82, respectively, without genetic disruptions. These slurries are applied to wounds around the margin of $C$. parasitica cankers created using a 1-cm diameter leather punch and a hammer and covered with masking tape to retard inoculum desiccation.

When compared to EU5/6 and water agar treatments, the SD328/82 formulation has much higher hypovirus recovery after 1 year, with nearly 95\% of treated cankers containing recovered hypovirus, followed by 56\% in EU5/6. Many of the sampled cankers are "complex" with two or more vic genotypes, or with a mixture of virulent and hypovirulent isolates recovered and may help to explain the only partial receipt of hypovirus by these wild-type isolates. 


\section{$\underline{\text { References }}$}

Anagnostakis, S.L., 1977. Vegetative incompatibility in Endothia parasitica. Experimental Mycology, 1(4), pp.306-316.

Anagnostakis, S.L., 1982. Biological control of chestnut blight. Science, 215(4532), pp.466-471.

Anagnostakis, S.L., Hau, B. and Kranz, J., 1986. Diversity of vegetative compatibility groups of

Cryphonectria parasitica in Connecticut and Europe. Plant Disease, 70(6), pp.536-538.

Anagnostakis, S.L., 1987. Chestnut blight: the classical problem of an introduced pathogen. Mycologia, 79(1), pp.23-37.

Linder-Basso, D., Dynek, J.N. and Hillman, B.I., 2005. Genome analysis of Cryphonectria hypovirus 4, the most common hypovirus species in North America. Virology, 337(1), pp.192-203.

Biraghi, A., 1953. Possible active resistance to Endothia parasitica in Castanea sativa. In Report Congress International Union Forest Research Organization (Vol. 11, pp. 149-157).

Buck, K.W., 1986. Fungal virology-an overview. In: Buck, K.W. (Ed.), Fungal Virology. CRC Press, Boca Raton, FL, pp. 2-84.

Caten, C.E., 1972. Vegetative incompatibility and cytoplasmic infection in fungi. Microbiology, 72(2), pp.221-229.

Chen, B. and Nuss, D.L., 1999. Infectious cDNA clone of hypovirus CHV1-Euro7: a comparative virology approach to investigate virus-mediated hypovirulence of the chestnut blight fungus Cryphonectria parasitica. Journal of Virology, 73(2), pp.985-992.

Choi, G.H., Dawe, A.L., Churbanov, A., Smith, M.L., Milgroom, M.G., and Nuss, D.L., 2012. Molecular characterization of vegetative incompatibility genes that restrict hypo virus 
transmission in the chestnut blight fungus Cryphonectria parasitica. Genetics, 190, pp.113127.

Cortesi, P. and Milgroom, M.G., 1998. Genetics of Vegetative Incompatibility in Cryphonectria parasitica. Applied and Environmental Microbiology, 64(8), pp.2988-2994.

Cortesi, P., McCulloch, C.E., Song, H., Lin, H. and Milgroom, M.G., 2001. Genetic control of horizontal virus transmission in the chestnut blight fungus, Cryphonectria parasitica. Genetics, 159(1), pp.107-118.

Dawe, A.L., and Nuss, D.L., 2013. Hypovirus molecular biology: from Koch’s postulates to host self-recognition genes that restrict virus transmission. In Ghabrial, S.A. (Ed), Advances in Virus Research, Vol. 86, Academic Press, Burlington, pp.109-147.

Diskin, M., Steiner, K.C. and Hebard, F.V., 2006. Recovery of American chestnut characteristics following hybridization and backcross breeding to restore blight-ravaged Castanea dentata. Forest Ecology and Management, 223(1-3), pp.439-447.

Hepting, G.H., 1974. Death of the American chestnut. Journal of Forest History, 18(3), pp.61-67. Hillman, B.I. and Suzuki, N., 2004. Viruses in the chestnut blight fungus. Adv. Virus Res, 63(642), pp.423-472.

Huber, D.H. and Fulbright, D.W., 1994. Preliminary investigations on the effect of individual vic genes upon the transmission of dsRNA in Cryphonectria parasitica. In Proceedings of the International Chestnut Conference (pp. 15-19). West Virginia University Press Morgantown, West Virginia, USA.

Jacobs, D.F., 2007. Toward development of silvical strategies for forest restoration of American chestnut (Castanea dentata) using blight-resistant hybrids. Biological Conservation, 137(4), pp.497-506. 
Jaynes, R.A. and Elliston, J.E., 1980. Pathogenicity and canker control by mixtures of hypovirulent strains of Endothia parasitica in American chestnut. Phytopathology, 70(5), pp.453-456.

Liu, Y. and Milgroom, M.G., 1996. Correlation between hypovirus transmission and the number of vegetative incompatibility (vic) genes different among isolates from a natural population of Cryphonectria parasitica. Phytopathology, 86(1), pp.79-86.

MacDonald, W.L. and Fulbright, D.W., 1991. Biological control of chestnut blight: use and limitations of transmissible hypovirulence. Plant Dis, 75(7), pp.656-661.

Melzer, M.S., Dunn, M., Zhou, T. and Boland, G.J., 1997. Assessment of hypovirulent isolates of Cryphonectria parasitica for potential in biological control of chestnut blight. Canadian Journal of Plant Pathology, 19(1), pp.69-77.

Morris, T.J. and Dodds, J.A., 1979. Isolation and analysis of double-stranded RNA from virusinfected plant and fungal tissue. Phytopathology, 69(8), pp.854-858.

Myburg, H., Gryzenhout, M., Wingfield, B.D., Milgroom, M.G., Kaneko, S. and Wingfield, M.J., 2004. DNA sequence data and morphology define Cryphonectria species in Europe, China, and Japan. Canadian Journal of Botany, 82(12), pp.1730-1743

Papazova-Anakieva, I., Sotirovski, K., Cortesi, P. and Milgroom, M.G., 2008. Horizontal transmission of hypoviruses between vegetative compatibility types of Cryphonectria parasitica in Macedonia. European Journal of Plant Pathology, 120(1), pp.35-42.

Peever, T.L., Liu, Y.C., Wang, K., Hillman, B.I., Foglia, R. and Milgroom, M.G., 1998. Incidence and diversity of double-stranded RNAs occurring in the chestnut blight fungus, Cryphonectria parasitica, in China and Japan. Phytopathology, 88(8), pp.811-817. 
Pinchot, G. and Ashe, W.W., 1897. Timber trees and forests of North Carolina (No. 6). MI \& JC Stewart, public printers.

Stauder, C.M., Nuss, D.L., Zhang, D.X., Double, M.L., MacDonald, W.L., Metheny, A.M. and Kasson, M.T., 2019. Enhanced hypovirus transmission by engineered super donor strains of the chestnut blight fungus, Cryphonectria parasitica, into a natural population of strains exhibiting diverse vegetative compatibility genotypes. Virology, 528, pp.1-6.

Welch, A.J., Stipanovic, A.J., Maynard, C.A. and Powell, W.A., 2007. The effects of oxalic acid on transgenic Castanea dentata callus tissue expressing oxalate oxidase. Plant science, 172(3), pp.488-496.

Zhang, D.X., Spiering, M.J., Dawe, A.L., and Nuss, D.L., 2014. Vegetative incompatibility loci with dedicated roles in allorecognition restrict mycovirus transmission in cheatnut blight fungus. Genetics, 197, pp.701-714.

Zhang, D.X. and Nuss, D.L., 2016. Engineering super mycovirus donor strains of chestnut blight fungus by systematic disruption of multilocus vic genes. Proceedings of the National Academy of Sciences, p.201522219.

Zhebentyayeva, T., Chandra, A., Abbott, A.G., Staton, M.E., Olukolu, B.A., Hebard, F.V., Georgi, L.L., Jeffers, S.N., Sisco, P.H., James, J.B. and Nelson, C.D., 2013. Genetic and genomic resources for mapping resistance to Phytophthora cinnamomi in chestnut. Acta Hort 1019: 263-270, 1019, pp.263-270. 


\section{Chapter 2}

\section{Optimization of engineered super donor strains of Cryphonectria parasitica to reduce}

canker expansion in a forest setting

\section{Introduction}

The chestnut blight fungus Cryphonectria parasitica has decimated American chestnut (Castanea dentata) populations in North America over the last century following its accidental introduction from Asia on infected Castanea nursery stock (Hepting, 1974). Castanea dentata stems have remained in North American forests by repeatedly stump-sprouting from surviving root systems of the previously killed mature trees, each new generation eventually succumbing to the disease (Anagnostakis, 1982). With the destruction of such an important mast and timber species, efforts to control the pathogen have been extensive. In the early 1900’s, efforts to control the spread of the chestnut blight fungus focused on an unsuccessful cut-and-burn program ahead of the disease front (Hepting, 1974). In the 1980’s backcross breeding began between resistant Chinese chestnut (Castanea mollisima) and American chestnut with the intention to produce trees that are phenotypically similar to the American chestnut, but with the resistance of the Chinese chestnut (Diskin et al., 2006). Most recently, transgenic American chestnut trees containing a wheat gene that allows them to break down oxalic acid have been produced (Welch et al., 2007). While useful, these control efforts focus on improving disease resistance of the host species rather than controlling the fungus itself.

In the 1950 ’s, callused-over C. parasitica cankers were observed in Italy by plant pathologist Antonio Biraghi (Biraghi et al., 1953). Isolates recovered from similar cankers by mycologist Jean Grente displayed muted pigmentation, reduced sporulation, and reduced 
virulence when compared to wild type C. parasitica isolates (MacDonald et al., 1991). Further research showed that these phenotypic traits were caused by an infecting cytoplasmic hypovirus (Choi and Nuss, 1992) spread through hyphal anastomosis in which the hyphae of two separate colonies fuse to form one colony, allowing virus transfer to occur (Cortesi et al., 2001). However, not all colonies of C. parasitica can undergo hyphal anastomosis when paired. Five diallelic vegetative incompatibility (vic) genes control virus transmission through hyphal anastomosis, and typically, in order for individual colonies of C. parasitica to undergo hyphal anastomosis, the two individuals must share all five alleles (Cortesi et al., 2001). Consequently, a hypovirus-infected donor colony typically must be the same vic genotype as the recipient to spread the hypovirus. In Europe, hypovirulence has been more successful than in North America, likely due to the lower levels of vic genotypic diversity and higher resistance of European chestnuts.

To address this issue, Zhang and Nuss (2016) engineered super hypovirus donor (SD82/SD328) strains. These super hypovirus donor strains are disrupted at four of the five vic gene alleles that restrict hypovirus transmission. However, disruptions at the vic2 locus failed to produced donor-promoting activity, raising the need for two super donor strains with differing alleles at vic2 to ensure compatibility with all 64 known vic genotypes. As such, SD328 (Z211Z2) and SD82 (Z141-Z2) can be combined to produce a slurry that is able to “donate" hypovirus to C. parasitica recipient strains with any vic genotype. Zhang and Nuss (2016) observed hypovirus transmission to $100 \%$ of vic genotypes in laboratory assays.

Stauder et al. (2019) evaluated the feasibility of using SD strains to transmit hypovirus to cankers in vivo in a forest setting. A slurry of SD strains infected with the CHV1/EP713 hypovirus was applied to naturally occurring cankers using a punch application. After 1 year, 
nearly 95\% of all treated cankers were hypovirulent, showing a high success rate, but not quite the $100 \%$ seen in the laboratory. Follow-up pairing assays revealed the remaining $5 \%$ of isolates could be converted under lab conditions.

In order to explore if delivery of SD fungal strains could be further optimized to reduce canker expansion in a forest setting, three application methods and two hypoviruses were used in this study. The punch application, also used in the first field release of SD strains, was included, along with scratch and paint applications as outlined below. The hypovirus used in the previous study, CHV1/EP713 was included along with another, less debilitating hypovirus, CHV1/Euro7.

\section{Materials and methods}

\section{Study Area}

The study site was located immediately east of Jacob’s Road in a recent clear cut on Savage River State Forest (3959’07.90’N and 7902’82.58’W) near Grantsville, Maryland. The plot was established under APHIS permit \#17-131-101r and is in close proximity to the initial SD test site on Swamp Road (Stauder et al., 2019). American chestnut stems were scattered throughout a naturally regenerating stand of mixed oak-chestnut-hemlock forest in the earliest stages of stem exclusion. Most stems were from 5-12 years of age; uninfected, infected and/or dead stems existed at the site. A sufficient number of stems with zero-to-one infections/stem existed to conduct the release in an area approximately $60 \mathrm{~m}$ x $60 \mathrm{~m}$. Some chestnut stems were less than 1 m apart while others were $5 \mathrm{~m}$ or more. Trees were selected based upon their size and their complete absence or limited number of chestnut blight cankers at the time of the study's initiation. Given that trees were monitored for a minimum of 1 year post-treatment, only stems with a minimum circumference of $10 \mathrm{~cm}$ and a maximum of one canker covering no more than 
$25 \%$ of the circumference of the stem were included. Fifty-one trees were found to be of satisfactory size and without any infections. Ten trees were found with only 1 infection at the date of the initial site survey.

\section{Selection of Canker Initiation Isolate}

Representative isolates of two of the most common naturally occurring vic genotypes, 1112-11 (EU12) and 2112-11 (EU17), recovered from the initial SD test site in Maryland (Stauder et al., 2019), were used in pathogenicity screenings to select the canker initiation isolate for this experiment. In addition to their natural abundance, EU12 and EU17 vic genotypes were selected based on their high number of allelic differences from the super donor strains EU5 (2211-22) and EU6 (2111-22), which presents a natural barrier for hypovirus transmission in non-engineered hypovirulent strains (Zhang and Nuss 2016). Candidate EU12 and EU17 isolates, in addition to the super donor parent strain EP-155 (2211-22) (Zhang and Nuss, 2016), were transferred from long-term storage on glass filter paper to potato dextrose agar (PDA; Difco, Detroit, Michigan) medium and allowed to grow for approximately one week, after which $0.1 \%$ aqueous pepton (wt/vol) was added atop the plates which were subsequently scraped to help liberate conidia. The spore suspension was decanted into $5 \mathrm{ml} 0.1 \%$ pepton, vortexed, and spread onto individual plates using a sterilized cell spreader. After two days of growth, the plates were observed under a steroscope and 25 individual colony forming units (presumably single conidial colonies) were subcultured, two of which were selected for pathogenicity tests. The resulting six isolates (two isolates for each of three strains) were grown on PDA media and used to inoculate golden delicious apples to serve as a relative estimate of pathogenicity (Fulbright, 1984). The purpose of these assays were to help identify and avoid the use of hypervirulent strains that could expand and girdle trees before biocontrols have established (Stauder, 2016). Since most inoculations 
produced comparable areas of necrosis (EP155 produced slightly larger area of necrosis), EU12 single spore \#2 was chosen because of its high number of allelic differences and its relative lower virulence in comparison to EP 155 (Figure 1). This isolate will be referred to henceforth as the "canker initiation isolate.” Since the stems in the study site were of relatively small diameter, the lower virulence of the canker initiation isolate is vital to keep the stems alive as long as possible in order to obtain enough data to make meaningful comparisons.

\section{Canker Initiation}

Colonies of the canker initiation isolate were grown for 1 week on PDA, after which inoculum plugs were cut from the plates using a $5.5 \mathrm{~mm}$ diameter leather punch. For each tree included in the study, a canker was initiated at $50 \mathrm{~cm}, 100 \mathrm{~cm}$, and $150 \mathrm{~cm}$ from the soil line by removing bark using the $5.5 \mathrm{~mm}$ diameter leather punch. A fully colonized inoculum plug was inserted into the wound mycelial side facing the vascular cambium using a sterile laboratory needle, and the wound was taped over to prevent desiccation of inoculum and reduce contamination from environmental fungi. If no canker was present at the initiation site after three weeks of growth, new inoculations were initiated $2 \mathrm{~cm}$ directly to the right of the failed inoculation site. If a tree had a natural infection, it was used as a substitute for an artificial canker at 50cm, 100, or $150 \mathrm{~cm}$ inoculation, depending on which location was closest to the established canker. The natural infections were sampled 4 times around the perimeter of the canker using a bone marrow biopsy tool (Lee-Lok, Plainsboro, NJ) inserted into 96-well microtiter plates (Nalge Nunc International, Rochester, NY), transported back to the laboratory on ice, and stored at $-22^{\circ} \mathrm{C}$ until processed. To process, bark plugs were thawed, soaked for $14 \mathrm{~min}$ in a 1:10 commercial bleach-sterile water solution for surface disinfestation, and transferred onto glucose yeast-extract (GYE) agar amended with streptomycin-sulfate $(.1 \mathrm{~g} / \mathrm{L})$ and tetracycline-hydrochloride $(.01 \mathrm{~g} / \mathrm{L})$ antibiotic. 
Resulting C. parasitica isolates were maintained on Whatman GF/A 60-mm glass microfiber filter paper (GE Healthcare Bio-Sciences, Pittsburgh, PA, USA) and placed in individual coin envelopes for storage at $-22^{\circ} \mathrm{C}$ for long-term storage (Short et al., 2015). Isolates were genotyped according to methods described by Short et al. (2015). When multiple C. parasitica isolates were recovered from a single canker, the resulting isolates were assigned a letter (“A”, "B”, “C”, or “D”) and paired against one another on bromocresol green agar (Powell, 1995) in darkness to test for vic compatibility. Colonies of the same compatibility type will undergo hyphal anastomosis, in which hyphae of the colonies join together, exchanging cellular contents and effectively creating a single colony (Short et al., 2015). Colonies of different compatibility types will not undergo hyphal anastomosis, instead experiencing programmed cell death, and a visible barrier will form between the two isolates (Short et al., 2015). If all isolates were vegetatively compatible, only one representative isolate was retained on filter paper. If isolates were not compatible with one another, one representative isolate of each was retained on filter paper for future use.

\section{Treatment inoculum preparation}

Two hypoviruses, CHVI-Euro7 and CHV1-EP713, were used in preparing super donor treatment inoculum. Hypoviruses CHVI-Euro7 or CHV1-EP713 were introduced into each of the two virulent SD strains from previously infected isolates by anastomosis. CHV1-EP713-containing super donor strains were previously used for initial field studies conducted by Stauder et al. (2019). Due to the arrested growth of hypovirulent super donor isolates, inoculum was generated as follows: hyphae from mature cultures of SD328 and SD82 inoculum were scraped, added to 1 $\mathrm{ml}$ of sterile water and vortexed for 20 seconds, after which $0.5 \mathrm{ml}$ of the macerate was transferred onto a GYE/A plate and allowed to grow for 1 week. 
Since cankers were treated with a combination of super donor strains SD82 and SD328 with either CHV1-Euro7 or CHV1-EP713 hypovirus, a slurry containing both strains was created for subsequent treatment. To make the slurry, 5 plates / isolate of hypovirulent SD82 and hypovirulent SD328 grown on PDA at $20^{\circ} \mathrm{C}$ with a $16 \mathrm{~h} / 8 \mathrm{~h}$ light/dark cycle under cool fluorescent lamps for 14 days were blended until homogenous in a 4L Waring commercial-grade blender with $750 \mathrm{ml}$ of sterile water and $500 \mathrm{ml}$ of water agar. This was done separately for the CHV1-Euro7 and CHV1-EP713 hypoviruses. The Waring blender was sterilized with commercial bleach in between each inoculum preparation. Upon completion, each of these slurries was put into separate, labelled, sterile Nalgene bottles for treatment and transported to the filed site on ice. All inoculum was used within $24 \mathrm{~h}$ of preparation.

\section{Canker Measurements, Treatment, and Sampling}

Artificially-initiated canker measurements were taken at six and one half weeks post-inoculation. Natural cankers, although variable in age, were measured at this time. Prior to treatment, the canker height, canker width, and stem circumference at the midpoint of the canker were measured in cm for each canker. All cankers were first outlined with a black permanent marker, after which inoculum slurry of super donor strains SD82 and SD328 containing hypovirus CHV1-Euro7 or CHV1-EP713 was applied. Separate paintbrushes were maintained to reduce the risk of contamination including one each for the CHV1-EP713 virus slurry on natural and artificial cankers and one each for the CHV1-Euro7 virus slurry on natural and artificial cankers.

Treatment of cankers also varied by application treatment: paint, punch, or scratch. Paint cankers were treated superficially by applying inoculum directly onto a $3.8 \mathrm{~cm}$ sterile paintbrush from the treatment bottles and applying the slurry onto the entirety of the canker, and slightly beyond the canker margin to the interface with healthy tissue. Punch cankers were treated as 
previously described (Stauder et al., 2019), using a $5.5 \mathrm{~mm}$ diameter leather punch to create circular wound approximately every $2 \mathrm{~cm}$ around the margin of the canker and one in the center of the canker. Inoculum was then applied directly to the holes using a squirt bottle and paint brush, and the excess inoculum was distributed evenly across the canker surface using a sterile $3.8 \mathrm{~cm}$ paintbrush. Scratch cankers were treated by using a modified beehive comb (Amazon, Seattle, WA, USA) (all but the 5 center tines were removed) to create long linear wounds along the entire canker, from the center to about $1 \mathrm{~cm}$ beyond the canker margin to the interface with healthy tissue. Unlike the previous two treatments, the canker was outlined after, not before, the application method was applied. Inoculum was then spread over the scratched canker using a 3.8 cm sterile paintbrush, extending to just outside of the canker's margin. All application methods are pictured in Figure 2.

Once cankers were treated, 12.7 x $12.7 \mathrm{~cm}$ laboratory pads were applied, non-absorbent facing side down, and secured to the stem using masking tape to retard drying of inoculum and prevent contamination from environmental fungi. For natural cankers that were larger than the 12.7 x $12.7 \mathrm{~cm}$ laboratory pads, two or more pads were used. The laboratory pads were removed from the cankers in September 2017, two weeks post-application. Any natural cankers which only yielded fungi other than $C$. parasitica during the initial sampling were re-sampled at this time.

In November 2017, February 2018, May 2018, and August 2018 canker length, canker width, and the stem circumference at the midpoint of the canker were measured. New cankers were recorded, measured as outlined above, sampled using a bone marrow biopsy tool, and treated with the same application type and hypovirus as the other cankers on the stem. 
Assessment of tree health status (alive, dead, top dead) and sampling of all cankers occurred at 12 MPI.

\section{Fungal Isolate Processing and Retention}

Bark plugs that were sampled from cankers were frozen in a $-22^{\circ} \mathrm{C}$ freezer until they could be processed. Processing was as previously described by Stauder et al. (2019). Following surface disinfestation, bark plugs were plated on GYE with the antibiotics streptomycin sulfate and tetracycline hydrochloride. All resultant fungal colonies with a characteristic C. parasitica phenotype, whether virulent or hypovirulent, were subcultured onto PDA. If more than one bark plug yielded C. parasitica, isolates were paired on bromocresol green as described above under canker initiation. Any isolates with novel vic genotypes within a canker were stored on filter paper and genotyped according to methods outlined in Short et al. (2015). If both virulent and hypovirulent phenotypes of the same genotypic background were sampled from the same canker, both isolates were retained.

\section{dsRNA extractions}

dsRNA was extracted based on a modified Morris and Dodds (1979) method described in detail by Stauder et al. (2019). Treatment isolates as well as virulent and hypovirulent isolates recovered from treated cankers were assayed. In C. parasitica, dsRNA is only present in $C$. parasitica colonies that are infected with a hypovirus. First strand cDNA was synthesized using GoScript Reverse Transcription System (Promega Corporation, Madison, USA) using random primers according to the manufacturer's directions with $4 \mu \mathrm{l}$ of purified dsRNA as described by Mlinarec et al. (2017). PCR was performed using a primer set specific for ORF A of the CHV-1 hypovirus (EP713-5 and R2280) (Allemann et al., 1999). Two sequencing primers (hvep1 and 
hvep2) located at conserved regions surrounding a variable region of ORF A (Gobbin et al., 2003) were selected for Sanger sequencing (Eurofins, Louisville, KY, USA). CHV1/713 and CHV1/Euro7 hypoviruses share 88\% sequence identity in the ORF A-surrounding regions targeted by the sequencing primers. Sequences of $8 \mathrm{HV}$ isolates, including SD treatment isolates were compared using pairwise BLASTn searches to the CHV1-EP713 (GenBank Accession: M57938) and CHV1-EURO7 genomes (GenBank Accession: AF082191) using pairwise blastn searches.

\section{DNA Extraction and vic Genotyping}

Mycelia from colonized C. parasitica plates were harvested and transferred to 1.5-ml Eppendorf tubes. Genomic DNA was extracted using primers (Integrated DNA Technologies, Coralville, IA, USA) and BioLine PCR kits (Bioline USA InC., Taunton, MA) in 26- $\mu$ l reaction mixtures containing $1 \mu$ l genomic DNA, $10 \mu \mathrm{l}$ nuclease-free water, $12.5 \mu \mathrm{l}$ BioLine PCR master mix, and $2.5 \mu \mathrm{l}$ primers (as described below). In three-primer multiplex assays, $0.83 \mu \mathrm{l}$ of each primer at $10 \mathrm{pmol}$ was used, whereas in four-primer assays, $0.625 \mu \mathrm{l}$ of each primer at $10 \mathrm{pmol}$ was used. Thermal cycling profiles were $95^{\circ} \mathrm{C}$ for 2 min, 34 cycles of $95^{\circ} \mathrm{C}$ for $30 \mathrm{~s}$, the respective annealing temperature for $30 \mathrm{~s}, 72^{\circ} \mathrm{C}$ for $105 \mathrm{~s}$, and then a final extension of $72^{\circ} \mathrm{C}$ for $10 \mathrm{~min}$. Optimal annealing temperatures for the six PCR assays were the following: vic2, vic3a, vic4, and vic7, $60^{\circ} \mathrm{C}$; vic6, $64^{\circ} \mathrm{C}$; and vic1a, $65^{\circ} \mathrm{C}$. For gel electrophoresis, $4 \mu \mathrm{l}$ of $1 \mathrm{X}$ SYBR gold (Invitrogen, Grand Island, NY, USA) and $4 \mu \mathrm{l}$ of 5X loading dye (5Prime, Gaithersburg, MD) were added to PCR products, which then were loaded onto a 1.5\%, wt/vol, agarose gel (Amresco, Solon, OH, USA) made with 0.5\% Tris-borate-EDTA buffer (Amresco, Solon, OH, USA). Electrophoresis was performed at $115 \mathrm{~V}$ for 1 to $2 \mathrm{~h}$, and bands were visualized on a UV transilluminator (Bio-Rad, Hercules, CA, USA). For size comparison, 100-bp and 1-kbp 
molecular ladders (Omega Bio-tek, Norcross, GA, USA) were included in gels. Multilocus vic genotypes were determined from gel images of the six PCR assays and compared with known multilocus genotypes of the 64 EU tester strains.

\section{Statistical analysis}

Statistic data were analyzed using JMP and SAS software (JMP®, Version Pro 12.2, SAS Institute Inc., Cary, NC, Copyright @2015; SAS®, Version 9.4, SAS Institute Inc., Cary, NC, Copyright (C2002-2012). Significance criterion alpha for all tests was 0.05. Canker size comparisons executed using a repeated-measures ANOVA followed by a Tukey-Kramer significance test. Tree health status evaluated using a Cochran-Mantel-Haenszel General Association test.

\section{$\underline{\text { Results }}$}

\section{Canker Area}

The effect of six treatment formulations (inoculum application x hypovirus) on canker expansion was determined by comparing canker linear growth measurements of artificial cankers obtained quarterly between August 2017 and August 2018. Canker area was calculated using the formula $(\mathrm{l}+\mathrm{w}) / 2$ (Bauman, 2015). Overall, the area of cankers treated using the paint application type was significantly larger than cankers treated with either punch or scratch application types (TukeyKramer, $\mathrm{p}=<0.0001$ ) (Figure 3). Additionally, the area of cankers treated with the CHV1-Euro7 hypovirus were significantly smaller than those treated with the CHV1-EP713 hypovirus (Tukey-Kramer, p=0.0269) (Figure 4). When testing interactions, there were significant differences between all paint $\mathrm{x}$ virus combinations (Tukey-Kramer, all $\mathrm{p}<0.05$ ) compared to all other treatments with the exception of paint CHV1-Euro7 and paint CHV1-EP713 with scratch 
CHV1-EP713. Interestingly, there was a significant difference between the area of scratch cankers treated with the CHV1-Euro7 and CHV1-EP713 hypoviruses (Tukey-Kramer, p = $0.0042)$.

Differentiation of canker area between paint and the two other application types did not occur until 6 months post-inoculation (MPI), after which the area of cankers increased dramatically relative to the other two application types (Figure 3). Likewise, differentiation of canker area between CHV1-Euro7 and CHV1-EP713 hypoviruses was not observed until 6 MPI when the size of CHV1-EP713 treated cankers surpassed those treated with CHV1-Euro7 (Figure 4). At the initiation of the study punch cankers were larger, although not significantly, compared to scratch cankers (Figure 4). Differentiation between the CHV1/Euro7 and CHV1/EP713 hypoviruses is most pronounced within the scratch application method (Figure 5).

\section{Mortality}

Fifty total trees were included in this study. Over the 12-month observation period, only two trees died, and six trees had girdling cankers despite treatment (Figure 6). There was a significant association between application type (paint, punch, scratch) and tree status (alive, dead, girdled) (Cochran-Mantel-Haenszel General Association, p=0.0174). Paint CHV1-EP713 treatment resulted in the highest number of stem girdling cankers and dead stems, followed by paint CHV1/Euro7, and punch CHV1/EP713 (Table 5). No other treatments resulted in dead stems or stem girdling cankers at 12 MPI. Because surviving and healthy stems treated with the punch and scratch application types had similar or larger numbers of new cankers when compared to those stems treated with the paint application type, it appears that compromised tree health status is strongly influenced by application type (N=50) (Table 5). 


\section{Recovery of $C$. parasitica}

C. parasitica was recovered from $42 \%$ of samples from natural and artificial cankers across all treatments. Of all samples, $12 \%$ were hypovirulent C. parasitica isolates and $30 \%$ were virulent. Of interest was a subset of 3 virulent and 2 hypovirulent $C$. parasitica isolates with brown phenotypes, indicative of either SD strains lacking hypovirus or progeny of SD strains resulting in a brown morphotype (Figure 7). SD strains were recovered from four cankers at $12 \mathrm{MPI}$, showing that SD strains can persist in $C$. dentata stems in a forest setting. In addition to $C$. parasitica, 57\% of plugs yielded one of several environmental fungi known to colonize chestnut blight cankers (Kolp et al., 2018).

\section{Hypovirus Recovery}

All C. parasitica isolates were evaluated for the presence of the white, slower-growing phenotypes typically associated with hypovirus infection. Isolates that displayed these phenotypes were scored as hypovirulent, while those isolates that displayed typical growth and orange pigmentation were scored as virulent. The punch CHV1-Euro7 treatment had the highest percentage of hypovirulent isolates, with $47 \%$ of recovered isolates containing hypovirus, and the paint CHV1-713 treatment had the least number of hypovirulent isolates, with only 11\% of all recovered isolates infected with hypovirus. Overall, cankers from paint treatments yielded fewer hypovirulent isolates (15\%) compared to cankers from the punch (39\%) and scratch (32\%) treatments (Table 3). Cankers treated with CHV1-Euro7 had a higher hypovirus recovery rate (35\%) compared to those treated with CHV1-713 (22\%). 


\section{dsRNA Extractions}

Isolates that exhibit muted or white pigmentation and limited growth are commonly considered hypovirulent. To confirm the presence of hypovirus, dsRNA extractions were performed on both hypovirulent and virulent phenotypes and assessed visually after gel electrophoresis to confirm the presence of hypovirus (Table 1). Of the nine isolates that displayed phenotypes consistent with a CHV1 hypovirus infection, including the four SD treatment isolates, dsRNA was successfully extracted from eight of them. Of the six isolates that displayed normal growth and orange pigmentation indicative of a virulent phenotype, including the canker initiation isolate, dsRNA was not recovered from any of them.

\section{Hypovirus Characterization}

Hypovirus dsRNA was successfully sequenced for eight isolates for which PCR products were generated and visually confirmed via electrophoresis (Table 2). This included both SD treatment isolates containing either CHV1/Euro7 or CHV1/EP713 hypovirus as well as 4 hypovirulent isolates representing 4 of the 6 treatments. GenBank blastn results of all CHV1/EP713 hypovirus-containing strains were >99\% identical to Cryphonectria hypovirus 1 (CHV1) complete genomic RNA (GenBank accession M57938) while the CHV1/Euro7 hypoviruscontaining strains were $>99 \%$ identical to Cryphonectria hypovirus 1 (CHV1) isolate Euro7, complete genome (GenBank accession AF082191). Canker 501-5, a natural scratch canker treated with CHV1-EP713, contained the CHV1-Euro7 hypovirus.

\section{Compatibility Testing}

Of the 204 naturally and artificially initiated cankers sampled at 12 MPI, at least one colony of C. parasitica was recovered from 169 cankers (Table 3). Thirty-five cankers yielded only 
environmental fungi such as Penicillium and Trichoderma species. In 109 of the 169 cankers from which C. parasitica was recovered, multiple colonies of $C$. parasitica were isolated. If multiple isolates of C. parasitica were recovered from a single canker, those isolates were paired on bromocresol green medium and grown in darkness for one week before being evaluated. A total of eight cankers yielded isolates that were not compatible with the other isolates from that canker and were stored and evaluated separately. All isolates were then paired against the canker initiation isolate, EU12. Of 347 recovered C. parasitica isolates, only 51 isolates were not compatible with EU12, 217 isolates were compatible, and 79 isolates had unclear incompatibility status.

\section{Genotyping}

A subset of C. parasitica isolates recovered from natural cankers prior to treatment were genotyped to elucidate vic diversity (Table 4). The vic genotype associated with tester strain EU12 was the only genotype recovered more than twice. Only three vic genotypes (EU27, EU42 and EU36) were not documented on Savage River State Forest within the last five years (Stauder et al., 2019).

\section{Discussion}

This study sought to explore if delivery of SD fungal strains could be further optimized to reduce canker expansion in a forest setting, by modifying either application method or hypovirus. The results, one-year post-treatment, support the conclusion that both application type and hypovirus used influence the expansion of cankers.

Although the CHV1-EP713 hypovirus has previously been reported to be more debilitating than the CHV1-Euro7 hypovirus (Chen et al., 1999), cankers treated with the CHV1- 
Euro7 hypovirus were significantly smaller overall at $12 \mathrm{MPI}$. The combination of the more debilitating CHV1-EP713 hypovirus and the super donor's already debilitated growth was likely too extreme to permit widespread hypovirus transmission, thus failing to limit expansion of virulent strains. Cankers treated with the paint application were significantly larger than those treated with the punch or scratch applications. Scratch application cankers were slightly larger than punch application cankers, although not significantly. This was somewhat surprising because the scratch application involves the disruption of the entire canker compared the punch application, which disrupts only a portion of the canker. Consequently, scratch application is best suited to efficiently treat complex cankers with multiple genotypes of $C$. parasitica. However, only 7 out of 157 cankers (both natural and artificial) in this study were determined to be complex and therefore, the utility of this application type could not be properly tested. Further research should be done on older, more established C. parasitica infections that are more likely to be complex to evaluate the scratch application method's efficacy. Based on results comparing the three application types, use of the punch application method combined with the CHV1-Euro7 hypovirus appears to be the most effective combination.

Differentiation in canker size between treatments was not significant until about 6 months post inoculation, when the size of cankers treated with the paint application type surpassed the other two applications. At this time, the size of CHV1-EP713 treated cankers surpassed the CHV1-Euro7 hypovirus. Similar trends were observed in the initial super donor field release site (Stauder et al., 2019). These results may indicate a lag time in hypovirus transmission and/or subsequent debilitation of virus-infected strains. Although some SD-treated cankers yielded hypobirulent isolates in as little as 4 weeks post-treatment, previous observations by Stauder et al. (2019) and Kolp et al. (2018) noted cases of C. parasitica cankers that were recalcitrant to 
CHV-1 transmission due to several factors: 1) canker complexity (cankers harbor multiple vic genotypes and therefore one or more resident vic genotype failed to receive hypovirus); and, 2) inhibition/competition with other resident environmental fungi.

It appears that host genetics, although important, did not strongly influence canker size. Clonal stems growing from the same root system but receiving different treatments did not respond similarly. In fact, $50 \%$ of trees with compromised tree health status were from a clump in which the other stem or stems were treated with different application types and/or hypoviruses, which remained healthy. This provides further evidence that super donor strains play a greater role in reducing canker size and consequently improving tree survivability than differences in host genetics.

Hypovirus transmission rates based on isolation of HV phenotypes from canker margins were the highest in natural and artificial cankers treated with the punch (39\%) and scratch (33\%) application methods, and lowest in paint (15\%) application cankers. In all three application types, cankers treated with the CHV1-Euro7 hypovirus had higher rates of hypovirus transmission. Higher hypovirus transmission rates corresponds directly to lower canker sizes in all six treatment types.

The low incidence of recovered hypovirus across all treatments may be due in part to competition from environmental fungi. August 2017-August 2018 was an exceptionally wet year. With high amounts of rainfall, sampling contamination from environmental fungi was very common, and many of the study cankers needed to be resampled 1-2 times in order to isolate $C$. parasitica. Many cankers even had superficial visual Pestalotia sp. colonization. Kolp et al. (2018) established that, as a poor competitor, virulent C. parasitica isolates were between $2 \%$ and 34\% smaller when grown on a plate with common environmental fungi, while hypovirulent 
isolates of C. parasitica experienced $18 \%$ and $54 \%$ inhibition. These data seem to support our findings, in that failure to isolate C. parasitica from cankers, whether virulent or hypovirulent, was associated with higher incidence of common wood-inhabiting environmental fungi mostly composed of Trichoderma, Penicillium, and Pestalotia species.

When sequencing hypovirus dsRNA extracted from representative isolates, CHV1-EP713 hypovirus was recovered from one canker which had been treated with CHV1-Euro7. Because inadvertent virus movement is possible through conidia of infected C. parasitica isolates, it is possible that stems treated with one hypovirus may occasionally encounter a second hypovirus from the environment. Given the close proximity of many of the stems in the study area, it is plausible that such an interaction, albeit rare, could have occurred. In all other extractions, the expected hypovirus was recovered, supporting the infrequency of such an interaction. Although hypovirus dsRNA extractions and sequencing are labor intensive and time consuming, this is a useful tool to help identify a hypovirus' role in canker expansion reduction.

The super donor's practicality is likely limited to orchard settings. Treatment is labor intensive, time intensive, and cankers often appear in areas that are out of reach without a ladder. When C. parasitica cankers appear in the canopy, they can go unnoticed and quickly girdle the stem, although the rest of the cankers on the stem have been treated. Owners of orchards such as those used by The American Chestnut Foundation for C. parasitica resistance breeding are more likely have the space and resources to properly monitor trees for new cankers and treat them as they arise. Furthermore, economically and ecologically valuable trees such as breeding or arboretum trees, are more likely to be worth the time, capital, and effort of treatment. The results of this study further confirm the field utility of super donor formulation of $C$. parasitica to serve 
as a vital resource for biological control of cankers for the ultimate woodland restoration of the American chestnut. 


\section{$\underline{\text { References }}$}

Anagnostakis, S.L., 1982. Biological control of chestnut blight. Science, 215(4532), pp.466-471.

Bauman, J.M., 2015. A comparison of the growth and asexual reproduction by Cryphonectria parasitica isolates infected with hypoviruses CHV3-County Line, CHV1-Euro7, and CHV1-Ep713. American Journal of Plant Sciences, 6, p.73.

Biraghi, A., 1953. Possible active resistance to Endothia parasitica in Castanea sativa. In Report Congress International Union Forest Research Organization (Vol. 11, pp. 149-157).

Choi, G.H., and Nuss, D.L., 1992. Hypovirulence of chestnut blight fungus conferred by synthetic infectious hypovirus transcript. Science, 264, pp.1762-1764.

Cortesi, P., McCulloch, C.E., Song, H., Lin, H. and Milgroom, M.G., 2001. Genetic control of horizontal virus transmission in the chestnut blight fungus, Cryphonectria parasitica. Genetics, 159(1), pp.107-118.

Diskin, M., Steiner, K.C. and Hebard, F.V., 2006. Recovery of American chestnut characteristics following hybridization and backcross breeding to restore blight-ravaged Castanea dentata. Forest Ecology and Management, 223(1-3), pp.439-447.

Hepting, G.H., 1974. Death of the American chestnut. Journal of Forest History, 18(3), pp.61-67.

Fulbright, D.W., 1984. Effect of eliminating dsRNA in hypovirulent Endothia parasitica. Phytopathology, 74(6), pp.722-724.

Welch, A.J., Stipanovic, A.J., Maynard, C.A. and Powell, W.A., 2007. The effects of oxalic acid on transgenic Castanea dentata callus tissue expressing oxalate oxidase. Plant science, 172(3), pp.488-496. 
Kolp, M., Fulbright, D.W. and Jarosz, A.M., 2018. Inhibition of virulent and hypovirulent Cryphonectria parasitica growth in dual culture by fungi commonly isolated from chestnut blight cankers. Fungal biology, 122(10), pp.935-942.

MacDonald, W.L. and Fulbright, D.W., 1991. Biological control of chestnut blight: use and limitations of transmissible hypovirulence. Plant Dis, 75(7), pp.656-661.

Short, D.P., Double, M., Nuss, D.L., Stauder, C.M., MacDonald, W. and Kasson, M.T., 2015. Multilocus PCR assays elucidate vegetative incompatibility gene profiles of Cryphonectria parasitica in the United States. Appl. Environ. Microbiol., 81(17), pp.5736-5742.

Stauder, C.M., Nuss, D.L., Zhang, D.X., Double, M.L., MacDonald, W.L., Metheny, A.M. and Kasson, M.T., 2019. Enhanced hypovirus transmission by engineered super donor strains of the chestnut blight fungus, Cryphonectria parasitica, into a natural population of strains exhibiting diverse vegetative compatibility genotypes. Virology, 528, pp.1-6.

Stauder, C. M. 2016. Comparisons of host susceptibility to isogenic virulent and hypovirulent [CHV1-infected] strains of Cryphonectria parasitica among Castanea hosts and plant tissue types. Masters Thesis, West Virginia University, Morgantown.

Zhang, D.X. and Nuss, D.L., 2016. Engineering super mycovirus donor strains of chestnut blight fungus by systematic disruption of multilocus vic genes. Proceedings of the National Academy of Sciences, p.201522219. 


\section{$\underline{\text { Tables and Figures }}$}

Table 1. Isolates of $C$. parasitica subjected to dsRNA extraction and their sources. X denotes presence/absence of dsRNA, indicating presence/absence of hypovirus. Source denotes the treatment the canker received.

\begin{tabular}{llccc}
\hline Canker & Source & dsRNA Absent & dsRNA Present & Hypovirus detected \\
\hline SD 82 (CHV1-EP713) & Canker Treatment Isolate & - & $\mathrm{X}$ & CHV1-EP713 \\
SD 328 (CHV1-EP713) & Canker Treatment Isolate & - & $\mathrm{X}$ & CHV1-EP713 \\
SD 82 (CHV1-Euro7) & Canker Treatment Isolate & - & $\mathrm{X}$ & CHV1-Euro7 \\
SD 328 (CHV1-Euro7) & Canker Treatment Isolate & - & $\mathrm{X}$ & CHV1-Euro7 \\
EU12 & Canker Initiation Isolate & $\mathrm{X}$ & - & - \\
$540-\mathrm{A3}$ & Punch CHV1-EP713 V & $\mathrm{X}$ & - & - \\
$521-2$ & Punch CHV1-EP713 HV & - & $\mathrm{X}$ & CHV1-EP713 \\
$537-\mathrm{B} 4$ & Scratch CHV1-EP713 V & $\mathrm{X}$ & - & - \\
$501-5$ & Scratch CHV1-EP713 HV & - & $\mathrm{X}$ & CHV1-Euro7 \\
$519-1$ & Paint CHV1-EP713V & $\mathrm{X}$ & - & - \\
$533-\mathrm{A3}$ & Punch CHV1-Euro7V & $\mathrm{X}$ & - & - \\
$507-3$ & Punch CHV1-Euro7 HV & - & $\mathrm{X}$ & CHV1-Euro7 \\
$527-2$ & Scratch CHV1-Euro7 HV & - & $\mathrm{X}$ & None \\
$524-\mathrm{B2}$ & Paint CHV1-Euro7 V & $\mathrm{X}$ & - & - \\
$508-3$ & Paint CHV1-Euro7 HV & $\mathrm{X}$ & - & - \\
\hline
\end{tabular}

Table 2. Hypovirus sequencing results for isolates from which dsRNA was recovered. Source denotes the treatment each canker received. The expected hypovirus was recovered from every extraction with the exception of canker 501-5. Percent identity and percent coverage are in comparison to the NCBI BLASTn top match.

\begin{tabular}{lllccc}
\hline Canker & Source & Virus Recovered & $\begin{array}{c}\text { Top Match } \\
\text { (NCBI Accession) }\end{array}$ & $\begin{array}{c}\text { Percent } \\
\text { Identity }\end{array}$ & $\begin{array}{c}\text { Percent } \\
\text { coverage }\end{array}$ \\
\hline SD 82 (CHV1-EP713) & Canker Treatment Isolate & CHV1-EP713 & M57938 & 99.87 & 99 \\
SD 328 (CHV1-EP713) & Canker Treatment Isolate & CHV1-EP713 & M57938 & 100 & 99 \\
SD 82 (CHV1-Euro7) & Canker Treatment Isolate & CHV1-Euro7 & AF082191 & 99.35 & 99 \\
SD 328 (CHV1-Euro7) & Canker Treatment Isolate & CHV1-Euro7 & AF082191 & 99.47 & 99 \\
$521-2$ & Punch CHV1-EP713 HV & CHV1-EP713 & M57938 & 99.74 & 99 \\
$501-5$ & Scratch CHV1-EP713 HV & CHV1-Euro7 & AF082191 & 99.15 & 100 \\
$507-3$ & Punch CHV1-Euro7 HV & CHV1-Euro7 & AF082191 & 99 & 100 \\
$527-2$ & Scratch CHV1-Euro7 HV & CHV1-Euro7 & AF082191 & 99.74 & 99 \\
\hline
\end{tabular}




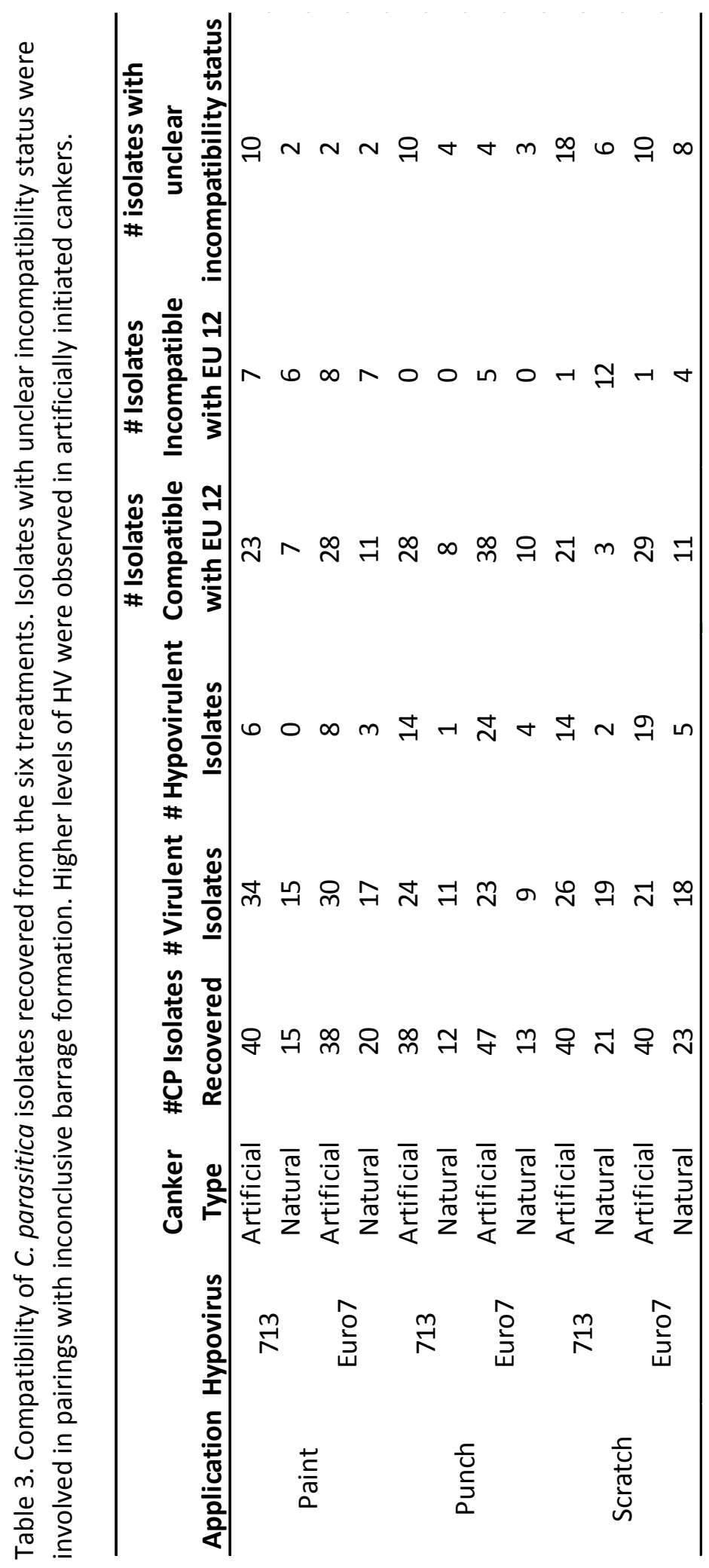


Table 4. Vic genotypes of representative isolates from natural cankers in each treatment type. Vic genotypes present in the pilot super donor study have been previously recorded in Savage River State Forest. Those not present in the pilot study were not previously recorded in Savage River State Forest.

\begin{tabular}{|c|c|c|c|c|}
\hline Application & Hypovirus & $\begin{array}{c}\text { vic } \\
\text { Genotype } \\
\end{array}$ & $\begin{array}{c}\text { EU Tester } \\
\text { Strain } \\
\end{array}$ & $\begin{array}{c}\text { Present in Pilot } \\
\text { Super Donor Study }\end{array}$ \\
\hline Paint & 713 & $1111-12$ & EU-27 & No \\
\hline " " & " " & $1111-11$ & EU-42 & No \\
\hline " " & " " & $1112-11$ & $\mathrm{EU}-12^{\mathrm{a}}$ & Yes \\
\hline " " " & " " " & $1211-11$ & EU-13 & Yes \\
\hline " " & Euro7 & $1112-22$ & EU-4 & Yes \\
\hline " " & " " & $1222-11$ & EU-45 & Yes \\
\hline Punch & 713 & $1112-11$ & $\mathrm{EU}-12^{\mathrm{a}}$ & Yes \\
\hline " " & " " & $2222-11$ & EU-33 & Yes \\
\hline " " " & " " " & 2221-11 & EU-46 & Yes \\
\hline " " & Euro7 & $1112-11$ & $\mathrm{EU}-12^{\mathrm{a}}$ & Yes \\
\hline Scratch & 713 & $2122-11$ & EU-10 & Yes \\
\hline " " & " " & $1112-11$ & $\mathrm{EU}-12^{\mathrm{a}}$ & Yes \\
\hline " " " & " " & $2221-11$ & EU-46 & Yes \\
\hline " " & Euro7 & 2121-11 & EU-36 & No \\
\hline " " & " " & $1212-11$ & EU-11 & Yes \\
\hline " " " & " " " & $1222-11$ & EU-45 & Yes \\
\hline
\end{tabular}

a Corresponds with vic genotype of canker initiation isolate 
Table 5. Summary data for individual study trees. Most trees with high numbers of new cankers do not also experience compromised tree health status.

\begin{tabular}{|c|c|c|c|c|c|c|}
\hline $\begin{array}{c}\text { Tree } \\
\text { ID }^{\mathrm{a}}\end{array}$ & $\begin{array}{c}\text { Initial } \\
\text { Diameter }\end{array}$ & $\begin{array}{c}\text { Application } \\
\text { Type }\end{array}$ & $\begin{array}{c}\text { Hypovirus } \\
\text { Used }\end{array}$ & $\begin{array}{c}\text { Initial } \\
\text { Cankers }\end{array}$ & $\begin{array}{c}\text { New } \\
\text { Cankers }\end{array}$ & $\begin{array}{c}\text { Tree Status } \\
12 \mathrm{MPI}\end{array}$ \\
\hline 500 & 24.3 & Paint & Euro 7 & 3 & 2 & Alive \\
\hline 501 & 21.2 & Scratch & Euro 7 & 3 & 5 & Alive \\
\hline 502 & 14.8 & Paint & 713 & 3 & 0 & Dead \\
\hline 504 & 14 & Punch & Euro7 & 3 & 1 & Alive \\
\hline 506 & 23.6 & Paint & Euro7 & 3 & 2 & Top Dead \\
\hline 507 & 17 & Punch & Euro 7 & 3 & 3 & Alive \\
\hline 508 & 13.5 & Paint & Euro7 & 3 & 0 & Alive \\
\hline $509-A$ & 18.5 & Scratch & Euro7 & 3 & 0 & Alive \\
\hline $509-B$ & 16.2 & Punch & 713 & 3 & 0 & Alive \\
\hline $510-A$ & 16 & Paint & Euro 7 & 3 & 0 & Alive \\
\hline $510-B$ & 14.1 & Scratch & 713 & 3 & 0 & Alive \\
\hline $511-A$ & 20 & Paint & Euro 7 & 3 & 0 & Alive \\
\hline $511-B$ & 17.4 & Punch & 713 & 4 & 1 & Top Dead \\
\hline 512 & 14.5 & Paint & Euro 7 & 3 & 1 & Top Dead \\
\hline $514-A$ & 23 & Paint & 713 & 3 & 3 & Alive \\
\hline $514-B$ & 14 & Scratch & 713 & 4 & 2 & Alive \\
\hline 516 & 24 & Punch & 713 & 4 & 1 & Alive \\
\hline $517-A$ & 22.2 & Scratch & Euro7 & 3 & 1 & Alive \\
\hline $517-B$ & 17.5 & Punch & 713 & 3 & 1 & Alive \\
\hline $518-A$ & 29.9 & Scratch & 713 & 3 & 1 & Alive \\
\hline 518-B & 24.1 & Scratch & Euro 7 & 3 & 3 & Alive \\
\hline 519 & 16.1 & Paint & 713 & 3 & 0 & Alive \\
\hline $520-A$ & 14.7 & Punch & Euro7 & 3 & 0 & Alive \\
\hline $520-B$ & 19.1 & Punch & Euro 7 & 3 & 0 & Alive \\
\hline 521 & 22.1 & Punch & 713 & 4 & 0 & Alive \\
\hline 522 & 16.8 & Scratch & Euro 7 & 3 & 1 & Alive \\
\hline 523 & 20.5 & Scratch & 713 & 3 & 0 & Alive \\
\hline $524-B$ & 18.1 & Paint & Euro7 & 3 & 0 & Alive \\
\hline 525 & 19.3 & Scratch & Euro 7 & 3 & 4 & Alive \\
\hline 527 & 18.7 & Scratch & Euro7 & 4 & 1 & Alive \\
\hline 528 & 19.2 & Paint & 713 & 3 & 1 & Alive \\
\hline $529-A$ & 17.5 & Punch & Euro 7 & 3 & 0 & Alive \\
\hline $529-B$ & 21.4 & Punch & Euro 7 & 4 & 0 & Alive \\
\hline $530-A$ & 21.8 & Scratch & 713 & 3 & 2 & Alive \\
\hline $530-B$ & 16.2 & Scratch & 713 & 3 & 0 & Alive \\
\hline 533-A & 16.4 & Punch & Euro7 & 3 & 4 & Alive \\
\hline $533-B$ & 14.8 & Paint & 713 & 3 & 0 & Top Dead \\
\hline 534-A & 35.8 & Punch & 713 & 3 & 3 & Alive \\
\hline 534-B & 27.1 & Punch & Euro7 & 4 & 2 & Alive \\
\hline $534-C$ & 17 & Scratch & 713 & 3 & 0 & Alive \\
\hline 535 & 18.5 & Punch & Euro7 & 3 & 0 & Alive \\
\hline 536 & 23.2 & Paint & 713 & 3 & 2 & Alive \\
\hline 537-A & 28 & Paint & 713 & 3 & 1 & Top Dead \\
\hline $537-B$ & 21 & Scratch & 713 & 3 & 2 & Alive \\
\hline $537-C$ & 28 & Punch & 713 & 3 & 4 & Alive \\
\hline 539 & 13.9 & Scratch & 713 & 3 & 2 & Alive \\
\hline $540-\mathrm{A}$ & 21.8 & Punch & 713 & 3 & 1 & Alive \\
\hline $540-B$ & 21.7 & Scratch & Euro 7 & 3 & 1 & Alive \\
\hline 541 & 16.8 & Paint & Euro 7 & 3 & 1 & Dead \\
\hline 543 & 17.8 & Paint & 713 & 3 & 4 & Top Dead \\
\hline
\end{tabular}

Letters A, B, and C denote stump sprouts that share a common root system and are presumably genetically identical. 


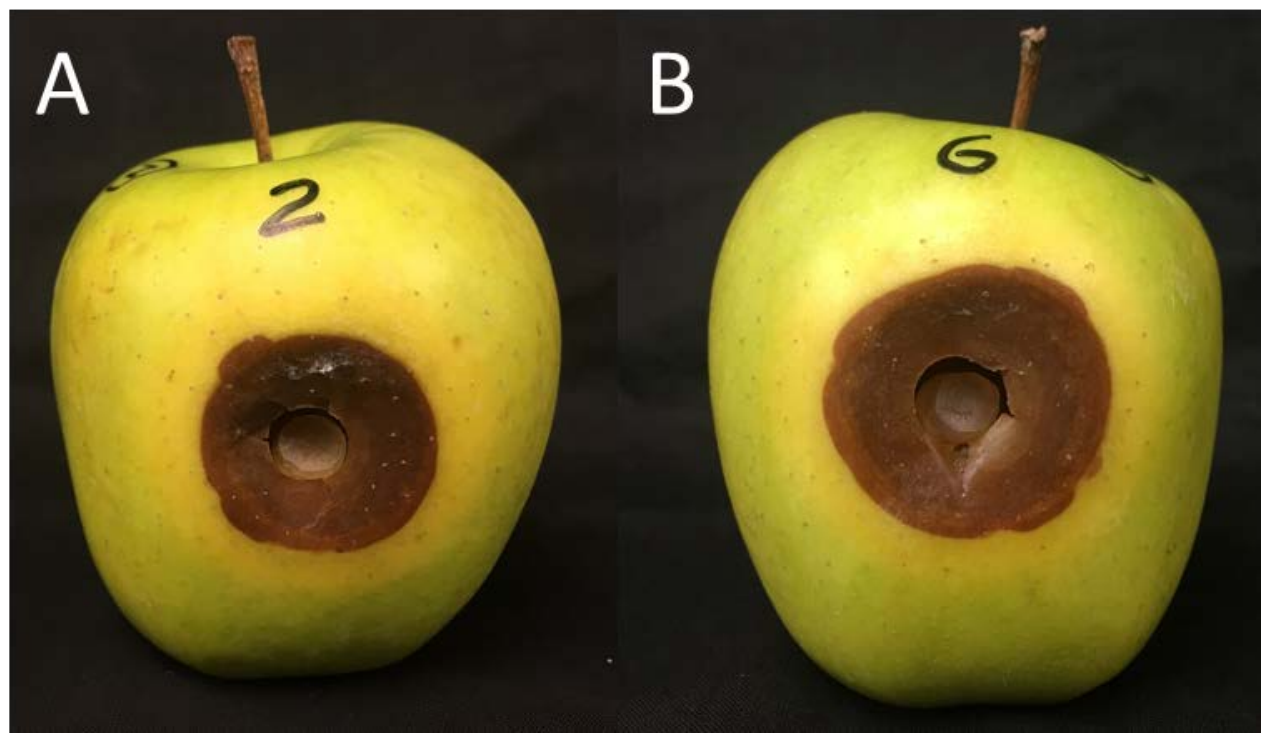

Figure 1. Pathogenicity assay of C. parasitica isolates in apples. A) EU12 single spore isolate \#2 canker initiation isolate B) EP155. Areas of necrosis caused by EP155 inoculations were larger than those caused by EU12 single spore isolate \#2. 

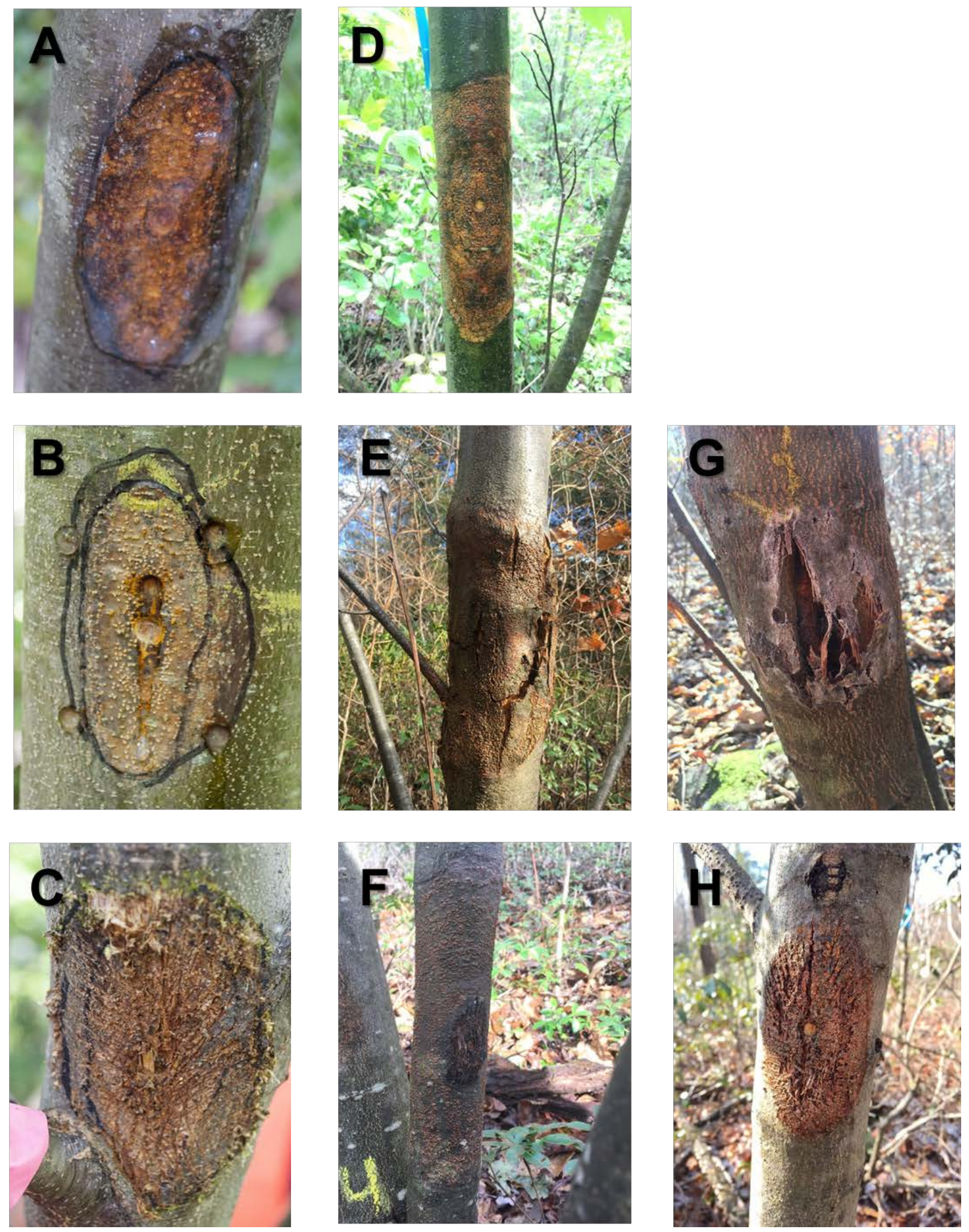

Figure 2. Canker treatments and outcomes. Application types include A) paint, B) punch, and $C$ ) scratch. Representative uninhibited and limited canker expansion are shown for punch ( $\mathrm{E}$ and $\mathrm{G})$ and scratch (F and $\mathrm{H}$ ), respectively. There were only uninhibited canker expansion examples for paint application (D). 


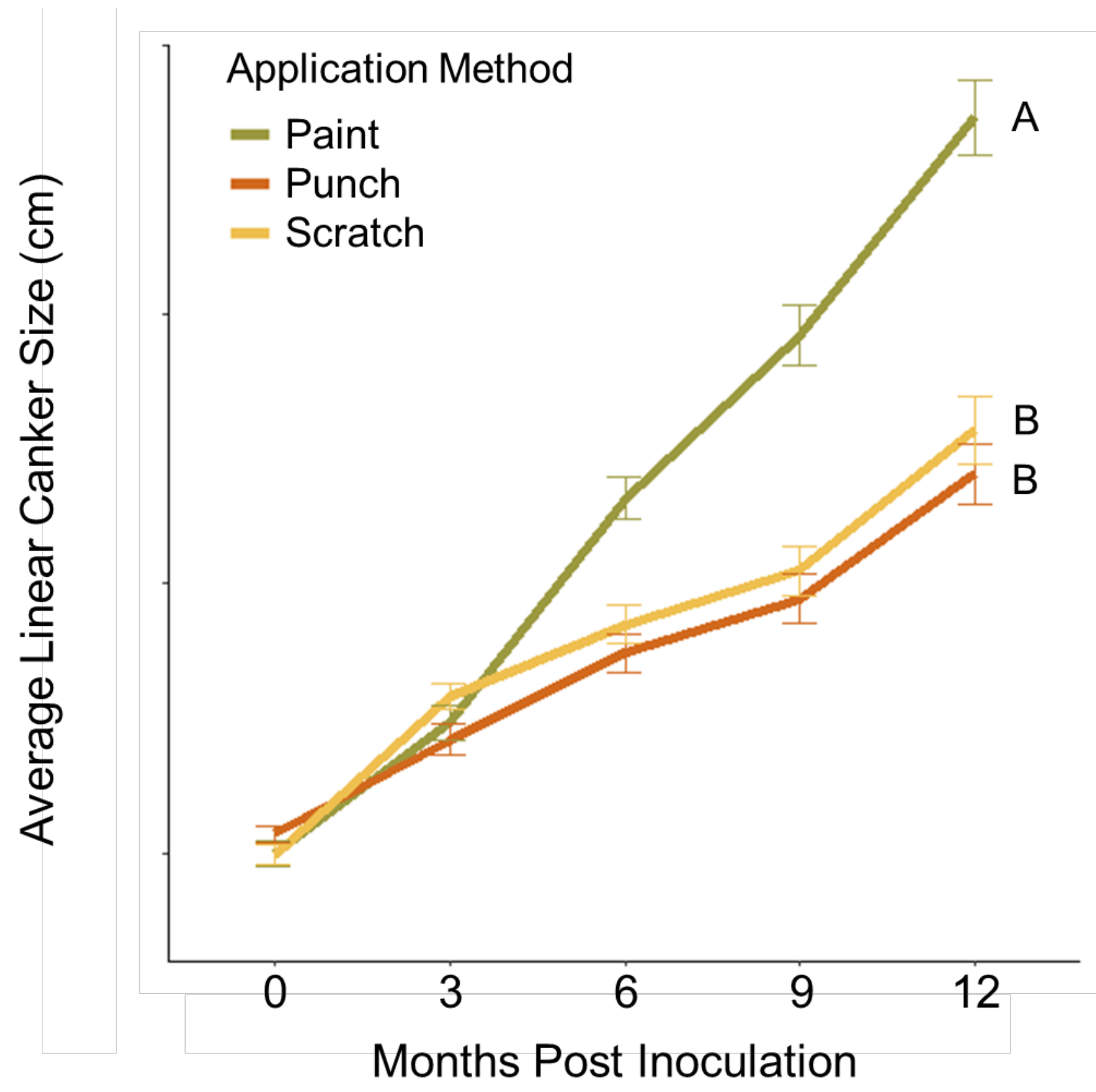

Figure 3. Average linear canker area $((\mathrm{L}+\mathrm{W}) / 2)$ by application method up to 12 MPI. Groups not connected by the same letter are significantly different. Error bars represent one standard error from the mean. 


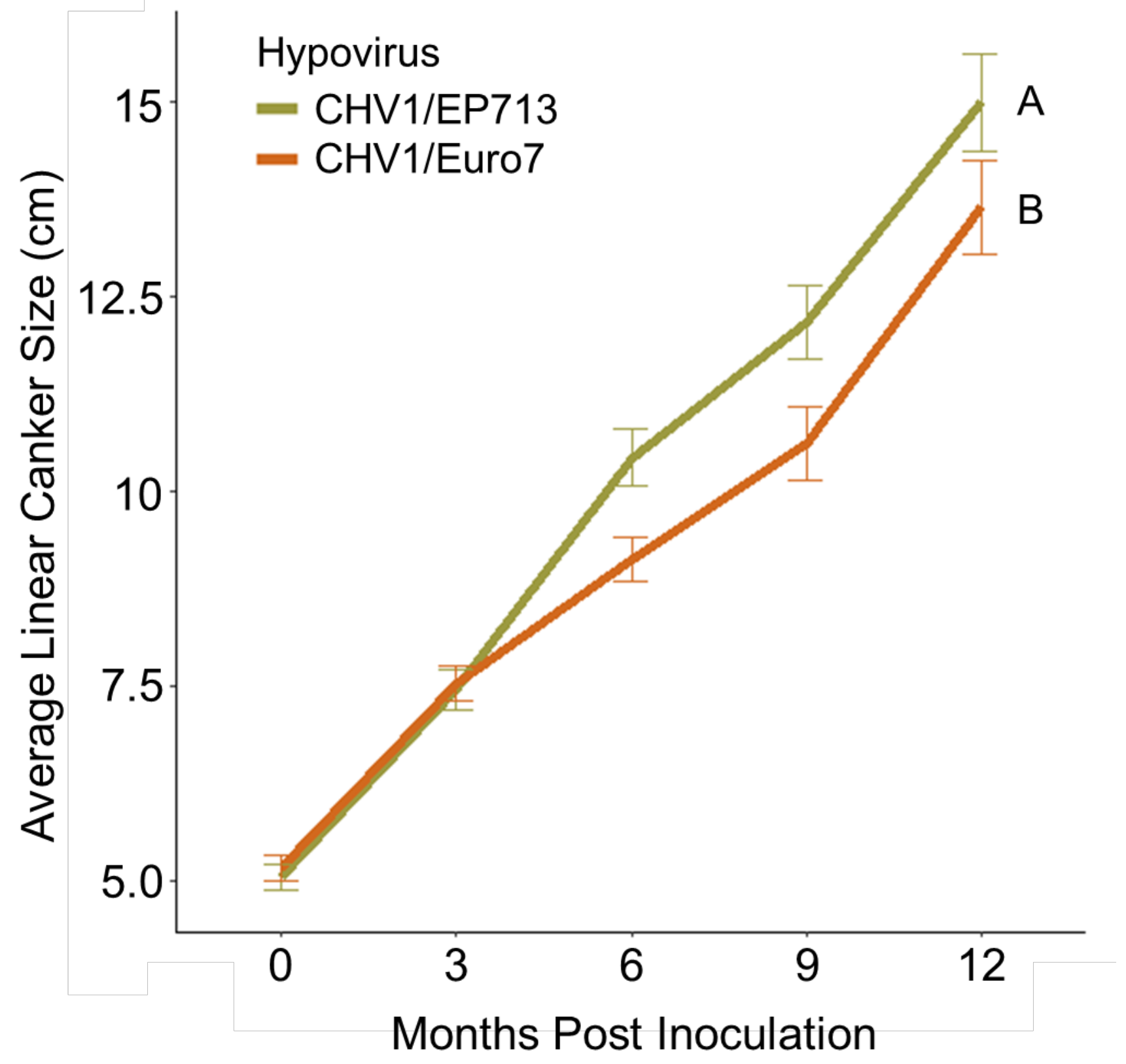

Figure 4. Average linear canker area $((\mathrm{L}+\mathrm{W}) / 2)$ by hypovirus up to $12 \mathrm{MPI}$. Groups not connected by the same letter are significantly different. Error bars represent one standard error from the mean. 


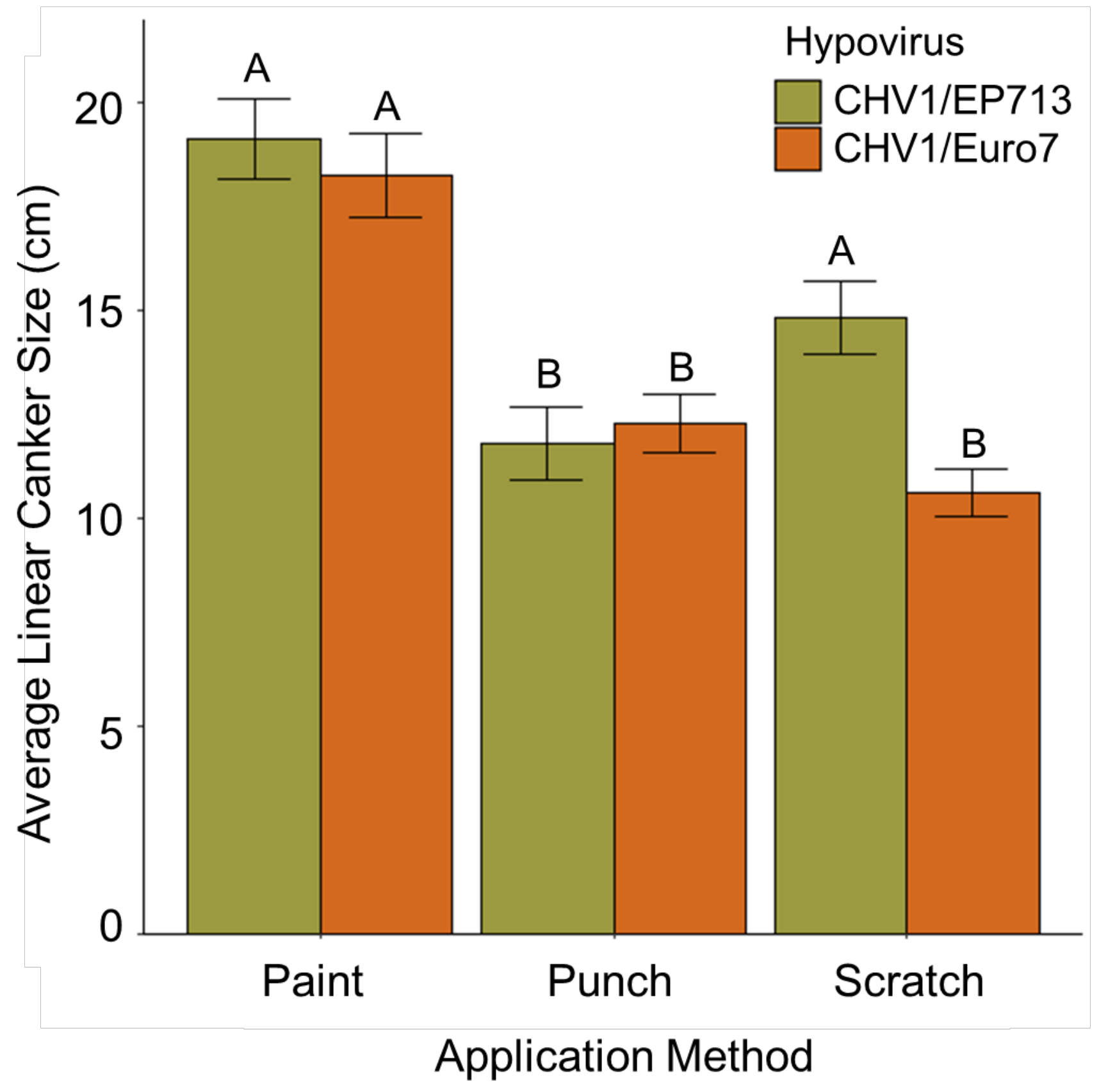

Figure 5: Average linear canker area by application type and hypovirus at 12 MPI. Groups not connected by the same letter are significantly different. Error bars represent one standard error from the mean. 


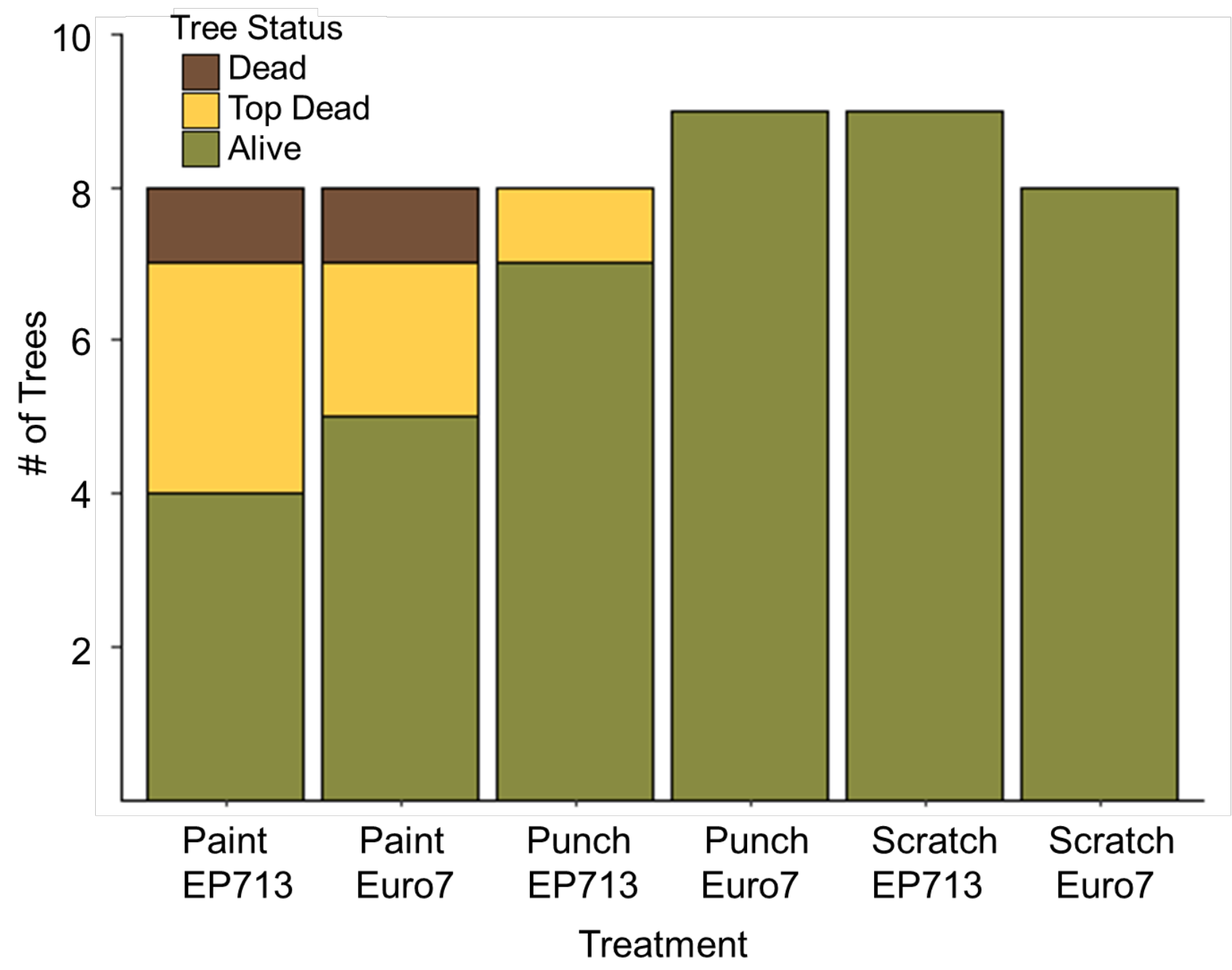

Figure 6. Tree status by treatment at 12 MPI. Compromised tree health status was caused mostly by cankers on trees in the Paint application method. Only one tree in the punch application method was compromised, and no trees in the scratch application method were compromised. 

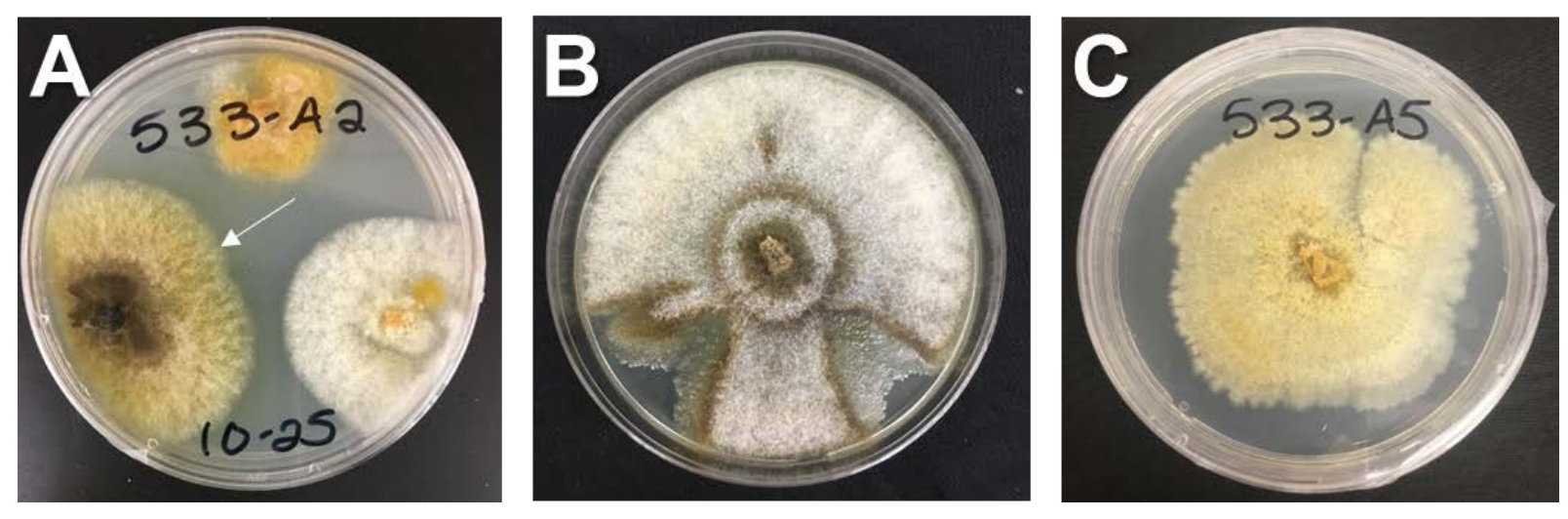

Figure 7. Atypical C. parasitica phenotypes recovered post-treatment including A) brown virulent, B) brown hypovirulent, and C) buff. 